

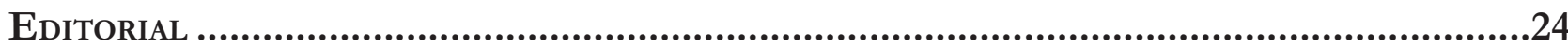

O Direito na fronteira da razão: Psicologia, neurociência e economia comportamental................... 24 Patrícia Perrone Campos Mello e Sergio Nojiri

I. NeURodireito: COGNIÇão, EMOÇÃo, JUÍZOS MORAIS E CIÊNCIA ..........................................26

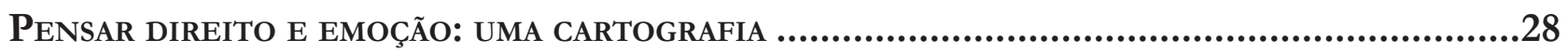

Nevita Maria Pessoa de Aquino Franca Luna

Neurodireito: o início, o fim E O MEIO

Carlos Marden e Leonardo Martins Wykrota

ENSAIO JURÍDICO SOBRE A RACIONALIDADE HUMANA: MAIORES, CAPAZES E IRRACIONAIS

André Perin Schmidt Neto e Eugênio Facchini Neto

DIVERGÊNCIAS DE PRINCÍPIO: ARGUMENTOS JURÍDICOS E MORAIS EM UM CENÁRIO DE DESACORDOS SOCIAIS

André Matos de Almeida Oliveira, Pâmela de Rezende Côrtes e Leonardo Martins Wykrota

CONSILIÊNCIA E A POSSIBILIDADE DO NEURODIREITO: DA DESCONFIANÇA À RECONCILIAÇÃO DISCIPLINAR.....

Thaís de Bessa Gontijo de Oliveira e Renato César Cardoso

MODELOS DE MORALIDADE

Molly J. Crockett

A INFELIZ BUSCA POR FELICIDADE No DiREITo

Úrsula Simões da Costa Cunha Vasconcellost, Noel Struchiner e Ivar Hannikainen

Além da liberdade: PersPeCtivas Em Nietzsche.

Lucas Costa de Oliveira

A mediaÇão de CONFlitos SOb a PERSPECTIVA do DESENVOLVIMENTO HUMANO: AS CONTRIBUIÇÕES DA PSICOLOGIA POSITIVA

Simone de Biazzi Ávila Batista da Silveira e Deise Brião Ferraz

Neuroimagiologia e aValiação de ResPonsabilidade

Nicole A. Vincent 
ANÁLISE CRÍTICA DA ORIENTAÇÃO DE CIDADÃOS COMO MÉTODO PARA OTIMIZAR DECISÕES PÚBLICAS POR MEIO DA TÉCNICA NUDGE.

Luciana Cristina Souza, Karen Tobias França Ramos e Sônia Carolina Romão Viana Perdigão

Políticas públicas e o deVer de monitoramento: “LEVANdo os Direitos A SÉrio". .252 Ana Paula de Barcellos

Nudges E POLÍticas PÚblicas: uM MECANISMO DE COMBATE AO TRABALHO EM CONDIÇÃo ANÁLOGA À DE ESCRAVO .267

Amanda Carolina Souza Silva, Débhora Renata Nunes Rodrigues e Saul Duarte Tibaldi

REDUZINDO A TRIBUTAÇÃO COGNITIVA: LIÇÕES COMPORTAMENTAIS PARA A DIMINUIÇÃO DOS EFEITOS PSICOLÓGICOS ADVERSOS DA POBREZA.............................................................288 Leandro Novais e Silva, Luiz Felipe Drummond Teixeira, Gabriel Salgueiro Soares e Otávio Augusto Andrade Santos

Políticas PÚBLICAS EM SUICÍDIO: DO PATERNALISMO CLÁSSICO AO PATERNALISMO LIBERTÁRIO E NUDGING

Davi de Paiva Costa Tangerino, Gabriel Cabral e Henrique Olive

Nudges COMO POLÍticA PÚbliCA PARA AUMENTAR O ESCASSO NÚMERO DE DOADORES DE ÓRGÃos PARA TRANSPLANTE

Roberta Marina Cioatto e Adriana de Alencar Gomes Pinheiro

Os PROGRAMAS DE INTEGRIDADE PARA CONTRATAÇÃO COM A ADMINISTRAÇÃO PÚBLICA ESTADUAL: NUDGE OU OBRIGAÇÃo LEGAL? UM OLHAR SOBRE AS DUAS PERSPECTIVAS .386

Cíntia Muniz Rebouças de Alencar Araripe e Raquel Cavalcanti Ramos Machado

Paternalismo libertário e Proteção JURídica do AMbiente: POR QUe PROTEger o AMBIENTE TAMBÉM DEVE SER PROTEGER AS LIBERDADES?

Mariana Carvalho Victor Coelho e Patryck de Araujo Ayala

Políticas PÚblicas baseadas EM EVIdÊNCIAS COMPORTAMENTAIS: REFLEXões A PARTIR do Projeto de Lei 488/2017 do Senado

Pâmela de Rezende Côrtes, André Matos de Almeida Oliveira e Fabiano Teodoro de Rezende Lara

III. ECONOMIA COMPORTAMENTAL: VIESES COGNITIVOS E POLÍTICAS PÚBLICAS .455

ECONOMIA COMPORTAMENTAL E DIREITO: A RACIONALIDADE EM MUDANÇA Marcia Carla Pereira Ribeiro e Victor Hugo Domingues

VIESES COGNITIVOS E DESENHO DE POLÍTICAS PÚBLICAS 
A neurociênCia da moralidade na tomada de DeCisões Jurídicas Complexas e No DESENHO DE POLÍTICAS PÚBLICAS

Erik Navarro Wolkart

Desvio de CARÁter ou SIMPLESMENTE HUMANO? ECONOMIA COMPORTAMENTAL APLICADA AO COMPORTAMENTO DESONESTO

Diana Orghian, Gabriel Cabral, André Pinto e Alessandra Fontana

Políticas Públicas e a ConcretizaÇão de direitos sociais: TOMAdA DE DECisão, ARQUITETURA DE ESCOLHAS E EFETIVIDADE

Ana Elizabeth Neirão Reymão e Ricardo dos Santos Caçapietra

BEHAVIORAL ECONOMICS E DIREITO DO CONSUMIDOR: NOVAS PERSPECTIVAS PARA O ENFRENTAMENTO DO SUPERENDIVIDAMENTO .568

Samir Alves Daura

A EDUCAÇÃo FORMAL PARA O CONSUMO É GARANTIA PARA UMA PRESENÇA REFLETIDA DO CONSUMIDOR NO MERCADO? UMA ANÁLISE COM BASE NA BEHAVIORAL LAW AND ECONOMICS (ECONOMIA COMPORTAMENTAL) 600

Marcia Carla Pereira Ribeiro e Edson Mitsuo Tiujo

LIBET, DETERMINISMO E CONSUMO: AS INFLUÊNCIAS DO MARKETING E A RELEVÂNCIA DA DELIBERAÇÃo CONSCIENTE NA SUPERAÇÃo CONDICIONAL DE HÁBITOS DE CONSUMO PERIGOSOS616 Émilien Vilas Boas Reis e Leonardo Cordeiro de Gusmão

CiÊNCIA DO DIREITO TRIBUTÁRIO, ECONOMIA COMPORTAMENTAL E EXTRAFISCALIDADE. .640 Hugo de Brito Machado Segundo

IV. CoMportamento JUdiCiAL: INFLUÊNCIA DE FATORES EXTRAJURÍDicos .660

FATORES METAPROCESSUAIS E SUAS INFLUÊNCIAS PARA A FORMAÇÃo DA DECISÃo JUDICIAL .662 Rogério Roberto Gonçalves de Abreu, Lúcio Grassi de Gouveia e Virgínia Colares

“A VIDA COMO ELA É": COMPORTAMENTO ESTRATÉGICO NAS CORTES Patrícia Perrone Campos Mello

A COMPOSIÇÃo do ÓRGão COLEGIAdo E SEUS EFEITOS NA TOMADA DE DECISÃo .720 André Garcia Leão Reis Valadares

Das 11 ilhas ao centro do arquipélago: os superpoderes do Presidente do STF DURANTE O RECESSO JUDICIAL E FÉRIAS .741 José Mário Wanderley Gomes Neto e Flávia Danielle Santiago Lima 
RAZÃo, EMOÇÃo E DELIBERAÇÃO: AS ADEQUAÇÕES REgIMENTAIS do SUPERIOR TribUNAL DE JUSTIÇA PARA A FORMAÇÃo DE PRECEDENTES EFICAZES

Peter Panutto e Lana Olivi Chaim

Heurística de ancoragem e fiXaÇÃo de danos morais em JUizados especiais Cíveis no Rio DE JANEIRO: UMA NOVA ANÁLISE 778

Fernando Leal e Leandro Molhano Ribeiro

LA PROTECCIÓN DE LOS DERECHOS POLÍTICOS FRENTE A LAS FUNCIONES DISCIPLINARIAS DE LAS AUTORIDADES ADMINISTRATIVAS: SUBSIDIARIEDAD Y DEFERENCIA EN EL SISTEMA INTERAMERICANO DE DERECHOS HUMANOS Jorge Ernesto Roa Roa

V. A influênCia do gÊNERo no PROCESSO DECisório JUdiCial

Como os Juízes decidem os Casos de estupro? ANALISANDo SENTENÇAS SOb A PERSPECTIVA DE VIESES E ESTEREÓTIPOS DE GÊNERO 826 Gabriela Perissinotto de Almeida e Sérgio Nojiri

GÊNERO E COMPORTAMENTO JUDICIAL NO SUPREMO TRIBUNAL FEDERAL: OS MINISTROS CONFIAM MENOS EM RELATORAS MULHERES?

Juliana Cesario Alvim Gomes, Rafaela Nogueira e Diego Werneck Arguelhes

Hércules, Hermes e a Pequena Sereia: uma reflexão sobre estereótipos de gênero, SUBPRESENTAÇÃo DAS MULHERES NOS TRIBUNAIS E (I)LEGITIMIDADE DEMOCRÁTICA DO PODER JUDICIÁRIO. .878 Jane Reis Gonçalves Pereira e Renan Medeiros de Oliveira

Prisão Cautelar de gestantes: análise do Fundamento filosófico da decisão do Habeas CoRpus N. 143.641 912

Artur César Souza e Giovania Tatibana de Souza

VI. Neurodireito APlicado ao direito E Ao Processo PENAL....................................926

CÉREbros QUe PUNEM: UMA REVISÃo CRÍTICA DA NEURoCIÊNCIA DA PUNIÇÃo .....................928 Ricardo de Lins e Horta

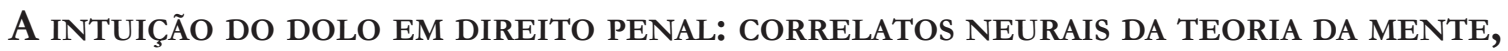
RACIOCÍNIO INDUTIVO E A GARANTIA DA CONVICÇÃO JUSTIFICADA. .946 Thiago Dias de Matos Diniz e Renato César Cardoso

As COMUNIDADES EPISTÊMICAS PENAIS E A PRODUÇÃo LEGISLATIVA EM MATÉRIA CRIMINAL..... 961 Stéphane Enguéléguélé 
DELINQUÊNCIA JUVENIL: RELAÇÕES ENTRE DESENVOLVIMENTO, FUNÇÕES EXECUTIVAS E COMPORTAMENTO SOCIAL NA ADOLESCÊNCIA .

André Vilela Komatsu, Rafaelle CS Costa e Marina Rezende Bazon

Límites TEMPORALES A LAS PENAS PRIVATIVAS DE LIBERTAD ATENDIENDO AL DESARROLLO PSICOSOCIAL.

Silvio Cuneo Nash

NEURolaw E AS PERSPECTIVAS PARA UMA ANÁLISE OBJETIVA DO COMPORTAMENTO SUGESTIONADO: REPERCUSSÃO DAS FALSAS MEMÓRIAS NA ESFERA PENAL

Mariana Dionísio de Andrade, Marina Andrade Cartaxo e Rafael Gonçalves Mota

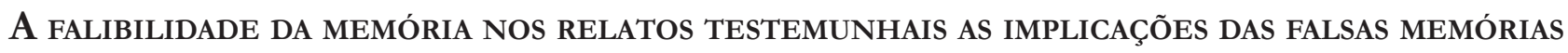
NO CONTEXTO DOS CRIMES CONTRA A DIGNIDADE SEXUAL

Caroline Navas Viana

A (IR)REPETIBILIDADE dA PROVA PENAL DEPENDENTE DA MEMÓRIA: UMA DisCUSSÃo COM BASE NA PSICOLOGIA DO TESTEMUNHO. 1058

William Weber Cecconello, Gustavo Noronha de Avila e Lilian Milnitsky Stein 


\section{La protección de los derechos políticos frente a las funciones disciplinarias de las autoridades administrativas: subsidiariedad y deferencia en el sistema interamericano de derechos humanos*}

\author{
The protection of political rights against \\ the disciplinary functions of administrative \\ authorities: subsidiarity and deference in the \\ inter-american human rights system
}

Jorge Ernesto Roa Roa**
* Artigo convidado

** Doctor en Derecho (summa cum laude) por la Universidad Pompeu Fabra de Barcelona. LL.M. en Ciencias Jurídicas Avanzadas por la Universidad Pompeu Fabra de Barcelona y LL.M. en Gobernanza y Derechos Humanos por la Universidad Autónoma de Madrid. Profesor de Derecho Constitucional y Derecho Público Comparado de la Universidad Externado de Colombia. Email: jorgeroaroa@gmail. com

\section{Resumen}

Este artículo analiza una de las tensiones más importantes entre la protección de los derechos políticos -tanto de los funcionarios públicos elegidos popularmente como de sus electores- $y$ las funciones disciplinarias de algunas autoridades administrativas. Esa tensión se profundiza en la medida en que las normas constitucionales nacionales y los tratados internacionales también protegen esas funciones de las autoridades disciplinarias con el fin de que estas persigan y sancionen la corrupción. El objetivo es preservar los recursos públicos que se destinan, entre otros fines, a la satisfacción de los Derechos Económicos, Sociales, Culturales y Ambientales. La investigación propone que, en el ámbito del Sistema Interamericano de Protección de los Derechos Humanos, esa tensión se puede superar mediante una fórmula de mutua deferencia que puede ser aplicada en todos los Estados. La deferencia debe existir de parte de la Corte Interamericana de Derechos Humanos con los Estados y de parte de las autoridades disciplinarias internas con los estándares establecidos por el tribunal interamericano. El artículo también señala las condiciones necesarias para que ocurra la mutua deferencia y advierte sobre los peligros de que la Corte Interamericana mantenga una interpretación textualista y austera del artículo 23 de la Convención Americana sobre Derechos Humanos.

Palabras clave: Derechos políticos. DESCA. Sistema Interamericano de Derechos Humanos. Democracia. Deferencia.

\section{Abstract}

This article analyzes one of the most important tensions between the protection of political rights - of both popularly elected officials and their constituents - and the disciplinary functions of some administrative authorities. This tension is deepened insofar as national constitutional norms and international treaties also protect the functions of disciplinary authorities 
with a view to enabling the prosecution and punishment of corruption. The objective is to preserve public resources which necessary, among other purposes, to the satisfaction of Economic, Social, Cultural and Environmental Rights. The research proposes that, within the framework of the Inter-American System for the Protection of Human Rights, this tension can be overcome through a formula of mutual deference that can be applied in all States. The deference must exist on behalf of the Inter-American Court of Human Rights in what concerns the States and on the part of the internal disciplinary authorities in what concerns the standards established by the Inter-American Court. The article also indicates the necessary conditions for mutual deference to occur and warns about the dangers of the Inter-American Court maintaining a textual and austere interpretation of Article 23 of the American Convention on Human Rights.

Keywords: Political rights. ESCER. Inter-American Human Rights System. Democracy. Deference.

\section{INTRODUCCIÓN}

El objetivo de este artículo es defender la existencia de una interpretación compatible de la Convención Americana sobre Derechos Humanos $(\mathrm{CADH})$ con las normas constitucionales y legales que facultan a algunas autoridades administrativas (e.g. Procuraduría General de la Nación) para sancionar a funcionarios públicos que han sido elegidos popularmente. La interpretación propuesta sugiere que esas autoridades administrativas actúan legítimamente cuando aplican un estándar alto y estricto en relación con las garantías judiciales establecidas en los artículos 8 y 25 de la CADH. En esos casos, las limitaciones introducidas por estas autoridades al artículo 23 de la CADH son legítimas en virtud de que han observado materialmente las condiciones establecidas por la Corte Interamericana de Derechos Humanos (Corte IDH).

En el artículo se defiende que esta interpretación de lege ferenda solo es plausible si tanto la Corte IDH como las autoridades nacionales actúan con deferencia. Eso implica que el tribunal interamericano aplique una versión material del principio de subsidiariedad y sea deferente con las autoridades nacionales que tienen funciones disciplinarias. Al mismo tiempo, las autoridades nacionales deben asumir y aplicar los más altos estándares sobre las garantías judiciales dentro de sus procesos disciplinarios con el fin de atender a la protección especial establecida en la jurisprudencia de la Corte IDH para los derechos políticos. En el artículo se indican claramente las diferencias entre el enfoque de deferencia y el margen de apreciación nacional para advertir que las funciones disciplinarias de las autoridades administrativas son compatibles con la CADH bajo un enfoque de deferencia que no requiere del margen de apreciación nacional utilizado por el Tribunal Europeo de Derechos Humanos.

La estructura del artículo es la siguiente. En la primera parte se describe la antinomia entre el artículo 23 de la CADH, tal y como ha sido interpretado por la Corte IDH, y las normas constitucionales y legales que facultan a la Procuraduría General de la Nación de Colombia para sancionar a los funcionarios públicos elegidos popularmente. También se dará cuenta de algunas de las razones por las cuales ocurre esa antinomia y de la complejidad de la misma. En la segunda parte se hace referencia a los mecanismos concretos del principio de subsidiariedad y a la deferencia dentro del Sistema Interamericano de Derechos Humanos (SIDH). Finalmente, se concretará la tesis sobre la compatibilidad de las funciones disciplinarias de la Procuraduría General de la Nación con una interpretación sistemática y material de los artículos 8, 23 y 25 de la CADH. 


\section{LOS DERECHOS POLÍTICOS PROTEGIDOS POR LA CADH FRENTE A LAS FUNCIONES DISCIPLINARIAS DE LAS AUTORIDADES ADMINISTRATIVAS}

La Corte IDH ha interpretado el artículo 23.2 de la CADH y ha fijado claramente los tres requisitos necesarios y concurrentes para que una restricción a los derechos políticos sea legítima. En efecto, para el tribunal interamericano, la restricción debe ser producto de una decisión judicial, adoptada por un juez competente y en relación con la comisión de un delito. Como lo ha indicado la propia Corte IDH:

"El artículo 23.2 de la Convención determina cuáles son las causales que permiten restringir los derechos reconocidos en el artículo 23.1, así como, en su caso, los requisitos que deben cumplirse para que proceda tal restricción. En el presente caso, que se refiere a una restricción impuesta por vía de sanción, debería tratarse de una "condena, por juez competente, en proceso penal". Ninguno de esos requisitos se ha cumplido, pues el órgano que impuso dichas sanciones no era un "juez competente", no hubo "condena" y las sanciones no se aplicaron como resultado de un "proceso penal", en el que tendrían que haberse respetado las garantías judiciales consagradas en el artículo 8 de la Convención Americana”.

Esa interpretación del artículo 23.2 de la CADH fue establecida en el contexto del caso López Mendoza $V$ s. Venezuela del año 2011. En esa decisión contenciosa, la Corte Interamericana condenó al Estado de Venezuela por la violación de los artículos 8 y 23 de la CADH en virtud de que un funcionario administrativo (Contralor General de la República) había impuesto dos sanciones de inhabilitación al señor Leopoldo López Mendoza. La decisión sancionatoria había sido adoptada en el contexto de un procedimiento administrativo y con base en unas faltas que no eran constitutivas de ningún delito.

La interpretación del artículo 23.2 de la CADH realizada en el contexto del caso López Mendoza Vs. Venezuela es vinculante para todos los Estados que han ratificado la CADH. Eso implica que el Estado colombiano también está obligado a observar ese estándar de protección de los derechos políticos de los funcionarios públicos elegidos popularmente. De esta premisa se infiere que existe una especie de antinomia entre la mencionada interpretación de la Corte IDH sobre el artículo 23.2 de la CADH y las normas constitucionales (artículo 277-6 y 278) y legales (Ley 734 de 2002) que facultan a la Procuraduría General de la Nación de Colombia para destituir e inhabilitar funcionarios públicos que han sido elegidos popularmente.

A la anterior conclusión se arriba después de contrastar el estándar interamericano que fija las tres condiciones para limitar legítimamente los derechos políticos de los funcionarios elegidos popularmente con el contenido de las normas que regulan la naturaleza y los procedimientos de la Procuraduría General de la Nación.

Para comprender integralmente el desarrollo y la complejidad de esa antinomia, es necesario hacer referencia a las decisiones de la Corte Constitucional de Colombia que han definido la constitucionalidad de las competencias de la Procuraduría General de la Nación y a la forma como esas competencias pueden coexistir con la mencionada interpretación del artículo 23.2 de la CADH (sección 1.1.). Además, es importante destacar la complejidad de esa contradicción normativa que pone en cuestión la eficacia de los mecanismos clásicos para superar una antinomia entre las normas jurídicas internas y el derecho internacional de los derechos humanos (sección 1.2.).

1 CORTE IDH. Caso López Mendoza Vs. Venezuela. Fondo Reparaciones y Costas. Sentencia de 1 de septiembre de 2011 Serie C No. 233, párr. 107. 


\subsection{La profundización de la antinomia por la vía de la jurisprudencia constitucional²}

El régimen de control disciplinario colombiano ha sido objeto de múltiples pronunciamientos de la Corte Constitucional. Además, la propia Ley 734 de 2002 ha sido demandada varias veces ante ese tribunal constitucional $^{3}$. Sin embargo, en relación con la jurisprudencia sobre la constitucionalidad de las competencias disciplinarias de la Procuraduría General de la Nación es importante destacar las sentencias C-028 de 2006 y SU-712 de 2013. Como se puede inferir, la primera decisión judicial se profirió antes de que la Corte IDH estableciera la interpretación del artículo 23.2 de la CADH en el año 2011, mientras que la segunda sentencia se dictó con posterioridad al caso López Mendoza Vs. Venezuela.

En la sentencia C-028 de 2006, la Corte Constitucional resolvió una acción pública de constitucionalidad interpuesta en contra de los artículos 44, 45 y 46 de la Ley 734 de 20024. Estas disposiciones legales facultan al Procurador General de la Nación para imponer las sanciones de destitución e inhabilidad a los servidores públicos, incluidos aquellos que han sido elegidos popularmente.

El principal argumento de los demandantes acusaba una contradicción entre el amplio poder sancionatorio que la Constitución y la ley atribuyen al Procurador General de la Nación y el artículo 23 de la Convención Americana sobre Derechos Humanos. En concreto, los demandantes consideraban que el proceso disciplinario adelantado por el Procurador General de la Nación no era compatible con las condiciones convencionales para la restricción de los derechos políticos mediante una condena, proferida por un juez competente dentro de un proceso penat. Asimismo, para los demandantes resultaba evidente que el Procurador no era un juez sino un funcionario administrativo, que podía iniciar procesos disciplinarios por razones diferentes a la comisión de un delito y que tal proceso no tenía las mismas garantías de un proceso penal.

En contra de los argumentos de los demandantes, la Corte Constitucional declaró la validez constitucional de las disposiciones demandadas. En sus fundamentos, el tribunal constitucional de Colombia tuvo en cuenta que existían disposiciones constitucionales (artículo 277-6) que expresamente facultaban al Procurador General de la Nación para ejercer el poder disciplinario contra los servidores públicos, incluidos aquellos que habían sido elegidos popularmente.

Además, la Corte Constitucional de Colombia sostuvo tres argumentos para declarar la constitucionalidad de las normas demandadas y la compatibilidad de las mismas con la CADH. En primer lugar, para el tribunal colombiano era necesario realizar una interpretación sistemática y teleológica de la CADH que tuviera en cuenta los cambios sociales y los nuevos desafíos de la comunidad internacional. Entre estas transformaciones debía considerarse, como un elemento central, el aumento de la corrupción en toda Latinoamérica ${ }^{6}$.

Además de la interpretación evolutiva, la Corte Constitucional sostuvo que era posible encontrar una interpretación que armonizara la $\mathrm{CADH}$ con otros tratados que no establecían derechos humanos ni protegían la dignidad humana, pero creaban obligaciones para los Estados en relación con la persecución y sanción de la corrupción?

\footnotetext{
2 Una versión extensa de esta sección se puede consultar en: ROA ROA, Jorge Ernesto. "Las antinomias entre las Constituciones y la Convención Americana sobre Derechos Humanos: el gran dilema del juez constitucional y convencional interamericano". En: SAIZ ARNAIZ, Alejandro. (Coord.); SOLANES, Joan; ROA, Jorge (Ed.). Diálogos judiciales en el Sistema Interamericano de Derechos Humanos. Valencia: Tirant lo Blanch, 2017. p. 139-148.

3 La ley 734 de 2002 ha sido objeto de múltiples demandas de constitucionalidad que fueron resueltas por la Corte Constitucional de Colombia, entre otras, en las Sentencias: C-181 de 2002, C-948 de 2002, C-1076 de 2002, C-124 de 2003.

4 Esta fue la primera demanda en la que el punto central de los argumentos consistía en la incompatibilidad de la ley 734 de 2002 con el artículo 23 de la Convención Americana sobre Derechos Humanos. Precisamente, por considerar que se trataba de un nuevo cargo de constitucionalidad, la Corte Constitucional consideró que las decisiones de control de la ley 734 de 2002 no constituían cosa juzgada. $5 \mathrm{CADH}$ (artículo 23.2). "2. La ley puede reglamentar el ejercicio de los derechos y oportunidades a que se refiere el inciso anterior, exclusivamente por razones de edad, nacionalidad, residencia, idioma, instrucción, capacidad civil o mental, o condena, por juez. competente, en proceso penal'. (cursiva fuera de texto)

6 CORTE CONSTITUCIONAL DE COLOMBIA. Sentencia C-028 de 2006, Fundamento Jurídico 6.4.

7 CORTE CONSTITUCIONAL DE COLOMBIA. Sentencia C-028 de 2006, Fundamento Jurídico 6.4.
} 
Finalmente, la Corte consideró que las convenciones de la Organización de Estados Americanos (OEA) y de la Organización de las Naciones Unidas (ONU) contra la corrupción permitían que los Estados establecieran e impusieran medidas disciplinarias para sancionar la corrupción de los servidores públicos ${ }^{8}$. En una referencia concreta al artículo 23 de la $\mathrm{CADH}$, la Corte Constitucional de Colombia sostuvo lo siguiente:

“[...] en lo que concierne a la imposición de restricciones legales al ejercicio del derecho de acceder a cargos públicos por la imposición de condenas penales, siendo interpretado sistemáticamente con otros instrumentos internacionales universales y regionales de reciente adopción en materia de lucha contra la corrupción, no se opone a que los Estados Partes en aquél adopten otras medidas, igualmente sancionatorias aunque no privativas de la libertad, encaminadas a proteger el erario público, y en últimas, a combatir un fenómeno que atenta gravemente contra el disfrute de los derechos económicos, sociales y culturales, consagrados en el Protocolo de San Salvador"'.

En síntesis, en la sentencia C-028 de 2006, la Corte Constitucional consideró que la interpretación sistemática de la $\mathrm{CADH}$, en relación con las obligaciones de Colombia respecto de la persecución de la corrupción, restaban fuerza a una supuesta tensión (antinomia) entre las disposiciones constitucionales que facultaban al Procurador para imponer las sanciones de destitución e inhabilitación y el texto de la CADH. Al mismo tiempo, esas obligaciones fueron el fundamento de la declaratoria de constitucionalidad de las disposiciones legales demandadas.

Después de seis años del pronunciamiento comentado anteriormente, la Corte Constitucional de Colombia seleccionó para revisión una decisión de tutela incoada por una ciudadana que había sido destituida del cargo de senadora de la República y a quien se le había impuesto la sanción de inhabilitación para ejercer cargos públicos por un periodo de dieciocho años. En su escrito, la ciudadana consideraba que le habían vulnerado sus derechos políticos porque las sanciones en su contra las había impuesto el Procurador General de la Nación con fundamento en el artículo 277-6 de la Constitución y en la Ley 734 de 2002.

En la Sentencia SU-712 de 2013, la Corte Constitucional enfrentó nuevamente el problema de la convencionalidad de las facultades disciplinarias del Procurador General de la Nación. La estructura argumentativa de la Corte Constitucional se basó en la reiteración de los mismos tres planteamientos esbozados en la Sentencia C-028 de 2006 (interpretación evolutiva, interpretación armónica y existencia de otros tratados que imponen obligaciones a los estados para perseguir la corrupción) ${ }^{10}$.

A diferencia del proceso de constitucionalidad del año 2008, en el proceso de revisión de tutela del año 2013 la Corte Constitucional de Colombia debió analizar la compatibilidad de su ordenamiento interno (Constitución y Ley) con la interpretación del artículo 23.2 de la CADH realizada por la Corte IDH en el contexto del caso López. Mendoza Vs. Venezuela. A pesar de la existencia de ese precedente interamericano, la Corte Constitucional de Colombia mantuvo su interpretación sobre el ordenamiento jurídico interno con base en los siguientes cinco argumentos.

En primer lugar, la Corte Constitucional sostuvo que el caso López Mendoza había ocurrido en un contexto jurídico y fáctico diferente. En especial, la Corte Constitucional se centró en destacar que la Constitución de Venezuela establecía la exigencia de decisión judicial para limitar los derechos políticos, frente a la Constitución de Colombia que faculta directamente al Procurador General de la Nación.

En segundo lugar, la Corte Constitucional afirmó que la CADH autoriza la imposición de sanciones administrativas o disciplinarias, siempre y cuando en el proceso de sanción se respeten las garantías judiciales del artículo 8 de la Convención. Como se indicará más adelante, este es uno de los pilares de la interpretación compatible del ordenamiento jurídico colombiano con la CADH que se defenderá en este capítulo.

8 CORTE CONSTITUCIONAL DE COLOMBIA. Sentencia C-028 de 2006, Fundamento Jurídico 6.4 
Por otra parte, el tribunal colombiano se basó en el voto concurrente formulado por el juez Diego García Sayán en el caso López. Mendoza. En ese voto, el juez interamericano señaló la necesidad de realizar una lectura restrictiva de la sentencia con el fin de evitar obstaculizar las acciones de los Estados para perseguir la corrupción.

En cuarto lugar, la Corte Constitucional afirmó que una interpretación extrema de los requisitos para la imposición de sanciones a los servidores públicos establecidas por la Corte IDH en el caso López Mendoza conduciría a vaciar las competencias para limitar derechos políticos de algunas autoridades internas, como el Procurador General y el Consejo de Estado. Finalmente, la Corte Constitucional sostuvo que la CADH se debía interpretar armónicamente con el diseño constitucional de cada Estado. De acuerdo con ese enfoque, se imponía el respeto a las facultades de la Procuraduría General de la Nación ${ }^{11}$.

A modo de conclusión, en la Sentencia SU-712 de 2013, la Corte Constitucional de Colombia sostuvo que la competencia del Procurador General de la Nación para investigar y sancionar a los servidores públicos elegidos popularmente se infería de un:

“[...] diálogo entre las normas constitucionales que regulan las garantías para el ejercicio de la actividad parlamentaria, con las normas del mismo nivel que atribuyen al Procurador facultades disciplinarias, de donde se advierte que las garantías institucionales de los congresistas no comprenden una suerte de inmunidad disciplinaria ante el Ministerio Público"’12.

Las normas que dialogan, para seguir la expresión que utilizó la Corte Constitucional, son los artículos 118, 123 y 277-6 de la Constitución de 1991. El primero establece que el Procurador General de la Nación tiene el deber de vigilar la conducta de quienes desempeñan funciones públicas; el segundo señala que se consideran servidores públicos a los miembros de las corporaciones públicas y; el tercero, faculta al procurador para vigilar a quienes ejercen funciones públicas e imponer sanciones, incluso a quienes han sido elegidos popularmente.

La estructura del mencionado diálogo es la siguiente: i) el procurador general puede vigilar y sancionar a quienes desempeñan funciones públicas, aun cuando sean elegidos popularmente; ii) desempeñan funciones públicas quienes pertenecen a las corporaciones públicas; iii) el Congreso es una corporación pública; iv) los congresistas desempeñan funciones públicas y pueden ser vigilados por el procurador.

Lo anterior significa que la jurisprudencia constitucional ha hecho una defensa de las facultades disciplinarias de la Procuraduría General de la Nación, incluso frente a la interpretación expresa de la Corte IDH sobre esa misma materia. Desde luego, la propia Corte Constitucional ha reiterado esta misma defensa en otras oportunidades ${ }^{13}$ y otros tribunales internos ${ }^{14}$, como el Consejo de Estado ${ }^{15}$ y el Consejo Superior de la Judicatura ${ }^{16}$, se han referido a esta misma contradicción del ordenamiento jurídico interno con la CADH. Algunos de esos tribunales han realizado una especie de control de convencionalidad para proteger los derechos políticos de los funcionarios destituidos e inhabilitados que fueron sancionados por la Procuraduría General de la Nación ${ }^{17}$. Adicionalmente, en virtud de que la Procuraduría General de la Nación ha ejercido nuevamente esas mismas competencias disciplinarias, se han suscitado pronunciamientos de la CIDH, tanto

11 CORTE CONSTITUCIONAL DE COLOMBIA. Sentencia SU-712 de 2013, Fundamento Jurídico 7.6.3.

12 CORTE CONSTITUCIONAL DE COLOMBIA. Sentencia SU-712 de 2013, Fundamento Jurídico 7.

13 CORTE CONSTITUCIONAL DE COLOMBIA. Sentencia T-514 de 2016.

14 TRIBUNAL ADMINISTRATIVO DE CUNDINAMARCA. Sección Segunda, Subsección A, Sentencia de 13 de enero de 2014, Proceso A.T. No. 2013-07052-00, Magistrado Ponente: José María Armenta Fuentes.

15 CONSEJO DE ESTADO. Sala Plena de lo Contencioso Administrativo. Sentencia del 15 de noviembre de 2017. Radicado No. 11001032500020140036000 . Magistrado Ponente: César Palomino Cortés.

16 CONSEJO SUPERIOR DE LA JUDICATURA. Sala Jurisdiccional Disciplinaria, Sentencia del 6 de marzo de 2014, Radicado No. 11001110200020130812001 , Salvamento de Voto del Magistrado Néstor Osuna Patiño.

17 TRIBUNAL CONTENCIOSO ADMINISTRATIVO DE LA GUAJIRA. Sentencia de 5 de junio de 2018. Radicado No. 44-001-23-40-000-2018-00062-00. Magistrada Ponente: Carmen Dalis Argote Solano. También las decisiones del Consejo de Estado previamente citadas. 
en la vía de las medidas cautelares ${ }^{18}$ como en la vía del procedimiento inicial de las peticiones individuales ${ }^{19}$.

\subsection{La complejidad de la antinomia: el fracaso de la interpretación conforme y del principio pro persona}

Las contradicciones entre las Constituciones nacionales y el derecho internacional de los derechos humanos son mucho más complejas que las antinomias entre las demás normas internas y el derecho internacional. En efecto, una contradicción normativa entre la Constitución y la CADH resulta especialmente difícil porque supone un verdadero dilema para el juez constitucional.

Cuando se trata de una verdadera antinomia, eso significa que el juez nacional no ha podido hallar ni una sola interpretación compatible de sus normas internas con la $\mathrm{CADH}$, tampoco ha podido interpretar armónicamente el contenido normativo de las disposiciones nacionales con el derecho internacional de los derechos humanos. Además, el principio pro persona no ha sido útil porque la mayor protección de un derecho por parte de las normas internacionales implica la menor protección de otros derechos también protegidos por esas normas internacionales y por las normas nacionales.

Ante el fracaso de la interpretación conforme, de la aplicación armónica y del principio pro persona, el juez interno se enfrenta al siguiente dilema: cumplir con la obligación de aplicar el derecho interno con la consecuente vulneración de un estándar interamericano en relación con la protección de un derecho humano o inaplicar su Constitución para aplicar directamente la CADH con el correlativo desconocimiento del contenido de otros derechos y valores fundamentales. Además del problema jurídico que esta situación representa, sobre los tribunales nacionales pesa la carga de su rol como jueces internos, la presión política y de la opinión pública. En definitiva, se trata de una situación compleja desde el plano jurídico, político y social.

Además de estos factores de articulación jurídica, en el caso concreto de los derechos políticos de los funcionarios elegidos popularmente y las funciones disciplinarias de la Procuraduría General de la Nación existe un problema adicional derivado de la austeridad de la jurisprudencia interamericana sobre derechos políticos y de los fundamentos que respaldaron la sentencia del caso López.Mendoza Vs. Venezuela.

En efecto, en la sentencia del caso López. Mendoza Vs. Venezuela, la Corte IDH se abstuvo de enfrentar el problema de la compatibilidad del artículo 23.2 de la CADH con los tratados internacionales que tienen como objetivo la persecución de la corrupción. En la nota a pie de página 208 de esa sentencia, la Corte IDH estableció que el tribunal: “[...] considera que la lucha contra la corrupción es de suma importancia y tendrá presente esa circunstancia cuando se le presente un caso en que deba pronunciarse al respecto"20.

Esta nota a pie de página presenta varios problemas. En primer lugar, se trata de una confesión de la Corte IDH sobre el conocimiento que ese tribunal tenía respecto de la colisión de su interpretación del artículo 23.2 de la CADH con las obligaciones de los Estados en materia de persecución de la corrupción. En segundo lugar, se trata de una aclaración insólita en la medida en que el marco fáctico descrito por la Corte IDH y el problema jurídico planteado en el caso López. Mendoza V s. Venezuela presentaban una relación directa con sanciones impuestas por actos de corrupción.

Si la Corte IDH hubiese asumido su rol como intérprete de la CADH en relación con otros tratados internacionales, habría resuelto el problema de la compatibilidad de las obligaciones internacionales que ordenan perseguir y sancionar la corrupción con los derechos políticos del artículo 23 de la CADH. Como ya ha quedado demostrado por los casos contenciosos que actualmente se tramitan ante la CIDH, la evasión del problema en una nota a pie de página no evitará que la Corte IDH se vea enfrentada muchas veces a

18 CIDH. Resolución 5 de 2014, Medida Cautelar No. 374-13. 18 de marzo de 2014, Fundamento 15.

19 CIDH. Informe de Fondo No. 130/17. Caso 13.044. Gustavo Francisco Petro Urrego. 25 de octubre de 2017.

20 CORTE IDH. Caso López. Mendoza Vs. Venezuela. Fondo Reparaciones y Costas. Sentencia de 1 de septiembre de 2011 Serie C No. 233, nota. 208. 
esta cuestión en la vía contenciosa, cuando sean sometidas a su conocimiento las peticiones individuales de ciudadanos colombianos que ya han presentado sus casos ante la CIDH.

Asimismo, es importante considerar que la interpretación del artículo 23.2 de la CADH puede afectar las competencias de varios órganos públicos de diferentes países de América Latina. Desde luego, este es un dato que no justifica per se un cambio de interpretación de la Corte IDH sino que sugiere la necesidad de abrir un diálogo institucional para encontrar una interpretación que haga compatibles la protección de los derechos políticos y las garantías judiciales con: i) las obligaciones internacionales impuestas a los Estados en materia de persecución y sanción de la corrupción y ii) las estructuras e instituciones nacionales encargadas de cumplir con esas obligaciones internacionales.

A partir de esta descripción de la antonimia, de sus complejidades y del desarrollo jurisprudencial, en la siguiente sección se hará referencia a los mecanismos que permiten garantizar la subsidiariedad material y la deferencia dentro del SIDH. Estas herramientas servirán de contexto para construir una propuesta de interpretación que sea compatible con el contenido normativo del artículo 23.2 de la CADH y con las funciones disciplinarias de la Procuraduría General de la Nación de Colombia.

\section{La deferencia y el PRinCiPIO de SUbSidiariedad en el Sistema InTERAmericano de Protección de los Derechos Humanos}

El sistema de protección de los derechos humanos creado en el marco de la OEA, como todos los sistemas regionales de protección de los derechos humanos, se rige por el principio de subsidiariedad ${ }^{21}$. Este principio es un elemento esencial para conciliar las competencias de los Estados, el pluralismo, la diversidad cultural y el valor intrínseco de los procedimientos nacionales de decisión con la existencia de unos valores universales y de unos objetivos globales que trascienden las fronteras estatales y que se expresan en los tratados sobre derechos humanos ${ }^{22}$. En términos generales, la subsidiariedad califica la relación entre dos instituciones, normas o sistemas normativos de manera que una de esas instituciones, normas o sistemas normativos complementa al otro solo cuando se cumplen determinadas circunstancias ${ }^{23}$.

El principio de subsidiariedad que rige a los sistemas de protección de los derechos humanos es una expresión del reconocimiento de que las instituciones domésticas de cada uno de los Estados son los escenarios en los cuales se deben adoptar las medidas necesarias para cesar, investigar, sancionar, reparar y garantizar la no repetición de las violaciones a los derechos humanos. El principio de subsidiariedad también refleja un concepto especial de implementación de los estándares internacionales sobre derechos humanos que centra sus esfuerzos en que las autoridades nacionales decidan los casos de violaciones a los derechos humanos con base en los criterios que habría utilizado el juez internacional ${ }^{24}$. Esta visión se opone a la idea de que todos los casos de violaciones a los derechos humanos sean conocidos por los tribunales supranacionales e internacionales.

21 Vid. CADH (Preámbulo). Un texto esencial sobre el origen histórico, el concepto y la aplicación del principio de subsidiariedad en los sistemas de protección internacional de los derechos humanos: Carozza, Paolo. "Subsidiarity as a Structural Principle of International Human Rights Law". The American Journal of International Law, vol. 97, no 1, 2003, pp. 38-79.

22 CAROZZA, Paolo. "Subsidiarity as a Structural Principle of International Human Rights Law". The American Journal of International Law, v. 97, n. 1, p. 63, 2003. Sobre la dificultad para construir un concepto preciso de subsidiariedad y justificarlo cuando se trata de la protección internacional de los derechos humanos: Besson, Samantha. "Subsidiarity in International Human Rights Law — What Is Subsidiary about Human Rights?”. The American Journal of Jurisprudence, v. 61, n. 1, p. 69-107, 2016.

23 NEUMAN, Gerald. "Subsidiarity". En: SHELTON, Dinah (Ed.). The Oxford Handbook of International Human Rights Law. Oxford: Oxford University Press, 2013. p. 362.

24 Algunas autoras se refieren a este fenómeno bajo la idea de los efectos reflejo de las sentencias de la Corte Interamericana. Vid. Acosta-López, Juana Inés; LONDOÑO LÁZARO, María Carmelina. "El papel de la justicia nacional en la garantía del derecho a un recurso efectivo internacional”. International Law. Revista Colombiana de Derecho Internacional, n. 16, p. 96, 2010. 
Como señala Gerald Neuman, la subsidiariedad impone una obligación y constituye una oportunidad para los Estados. La obligación proviene de la necesidad de que a nivel interno se establezcan las normas y los procedimientos para garantizar los derechos. La oportunidad deriva del hecho de que, cumplir adecuadamente con la anterior obligación, generará una menor intervención de los sistemas regionales de protección de los derechos humanos ${ }^{25}$.

En el mismo sentido, Paolo Carozza afirma que la subsidiariedad es un principio paradójico que, por una parte, limita la intervención de los tribunales internacionales cuando la protección estatal interna de los derechos es adecuada. Sin embargo, por otra parte, la subsidiariedad también es la fuente de legitimidad de la intervención de los tribunales internacionales cuando esta se requiere y justifica en razón de las fallas estatales en la protección de los derechos ${ }^{26}$.

En el ámbito de los sistemas regionales de protección de los derechos humanos existen diferentes mecanismos para implementar la dimensión procedimental del principio de subsidiariedad, inter alia, el agotamiento de los recursos internos o la fórmula de la cuarta instancia. Desde luego, el principio de subsidiariedad de los sistemas de protección de los derechos humanos se complementa con la deferencia que los tribunales internacionales muestran a favor de los Estados en el análisis de fondo de los casos (e.g. margen de apreciación nacional) y en las medidas de reparación o remedios que puede proferir un tribunal (deferencia remedial $)^{27}$.

Por ejemplo, en materia de reparación a las violaciones a los derechos humanos, el Tribunal Europeo de Derechos Humanos permite que los Estados adopten medidas de reparación adicionales a la justa compensación. Por el contrario, la Corte Interamericana adopta medidas de reparación integral y ordena la adopción de medidas de satisfacción y de garantías de no repetición que dejan poco margen a los Estados. Además, la supervisión del cumplimiento de las decisiones del Tribunal Europeo le corresponde exclusivamente al Consejo de Europa mientras que en América esas funciones las realiza tanto la propia Corte IDH como la Asamblea General de la OEA.

Aún más, en algunos casos, las medidas de reparación ordenadas por la Corte Interamericana son criticadas porque se confunden con las políticas sociales del Estado y van más allá del remedio del daño para dejar a la víctima en una situación cualitativamente mejor a la que tenía antes de sufrir el daño. Estas medidas, que se denominan transformadoras, han dado origen a discusiones interesantes sobre la función compensatoria o redistributiva de la reparación ${ }^{28}$. Esta discusión interamericana refleja que la deferencia en materia de reparaciones tiene un alcance menor en el Sistema Interamericano en comparación con lo que ocurre en el ámbito del Consejo de Europa.

Ahora bien, como se verá a continuación, en el marco del Sistema Interamericano se han aplicado los mecanismos de agotamiento de los recursos internos y la fórmula de la cuarta instancia mientras que se discute sobre el uso excepcional e implícito del margen de apreciación nacional.

25 NEUMAN, Gerald. "Subsidiarity". En: SHELTON, Dinah (Ed.). The Oxford Handbook of International Human Rights Law. Oxford: Oxford University Press, 2013. p. 365.

26 CAROZZA, Paolo. "Subsidiarity as a Structural Principle of International Human Rights Law". The American Journal of International Law, v. 97, n. 1, p. 44, 2003.

27 NEUMAN, Gerald. "Subsidiarity". En: SHELTON, Dinah (Ed.). The Oxford Handbook of International Human Rights Law. Oxford: Oxford University Press, 2013. p. 373-364.

28 HENAO, Juan Carlos. "Las formas de reparación en la responsabilidad del Estado: hacia su unificación sustancial en todas las acciones contra el Estado". Revista de Derecho Privado, n. 28, p. 277-366, 2015 y UPRIMNY, Rodrigo; GUZMÁN, Diana. "En búsqueda de un concepto transformador y participativo para las reparaciones en contextos transicionales". Revista Colombiana de Derecho Internacional, n. 17, p. 231-286, 2010. 


\subsection{El previo agotamiento de los recursos internos: reglas, excepciones y carga de la prueba}

En primer lugar, el agotamiento de los recursos internos es una vía de subsidiariedad negativa, según la cual, los órganos internacionales no pueden intervenir cuando dentro del sistema doméstico se adoptaron todas las medidas necesarias para reparar una violación a los derechos humanos. Dicho de otra manera, como el sistema de protección internacional de los derechos humanos es complementario del sistema interno de cada Estado, el primero solo puede intervenir cuando este último ha fallado. El mecanismo de la subsidiariedad mediante el agotamiento de los recursos internos se encuentra establecido en los artículos 46.1.a de la Convención Americana y 31.1 del Reglamento de la $\mathrm{CIDH}^{29}$.

Estas dos disposiciones establecen que los peticionarios deben manifestarle a la Comisión Interamericana los recursos judiciales internos que agotaron antes de acudir al Sistema Interamericano. En sus opiniones consultivas y en su jurisprudencia contenciosa, la Corte Interamericana ha precisado las características esenciales que deben satisfacer los recursos internos para ser considerados como requisitos de procedibilidad ante el Sistema Interamericano: disponibilidad, adecuación y efectividad.

Por una parte, los recursos deben estar disponibles y eso significa que deben estar previstos formalmente dentro del ordenamiento y ser de fácil acceso para los individuos. Además, la idoneidad o adecuación se refiere a la existencia de una relación directa entre la vulneración del derecho y la función del recurso para lograr el objetivo de superar esa situación de violación a los derechos humanos. Finalmente, la eficacia de los recursos internos significa que estos tengan el potencial para producir el resultado jurídico y fáctico para el cual fueron diseñados ${ }^{30}$.

Además de los anteriores aspectos, la Corte Interamericana ha analizado situaciones especiales en las que ha considerado el tiempo en que son resueltos los recursos judiciales internos, el grado de independencia de las autoridades judiciales ante las cuales se tramitan esos recursos, el contexto de violencia y terror que puede condicionar el resultado de los recursos internos o las competencias de las autoridades domésticas para hacer cumplir sus decisiones frente a los particulares y a las demás autoridades nacionales ${ }^{31}$.

Cuando el Estado considera que los peticionarios no han agotado los recursos internos, asume la carga de probar la existencia de los recursos, su disponibilidad, idoneidad, adecuación y efectividad ${ }^{32}$. El Estado puede introducir ese argumento dentro del procedimiento contencioso mediante la presentación de una excepción preliminar con el fin de que la Comisión Interamericana declare inadmisible la petición ${ }^{33}$. El Estado tiene la carga de presentar esa excepción preliminar durante la fase de admisibilidad del procedimiento

29 Sobre el agotamiento de los recursos internos en el ámbito del Sistema Interamericano: Burgorgue-Larsen, Laurence; ÚBEDA DE TORRES, Amaya. The Inter-American Court of Human Rights. Case Law and Commentary. Oxford: Oxford University Press, 2011. p. 129-145 y PASQUALUCCI, Jo M. The Practice and Procedure of the Inter-American Court of Human Rights. Cambridge: Cambridge University Press, 2013. p. 92-98. Sobre el agotamiento de los recursos internos en el ámbito del Sistema Europeo de Protección de los Derechos Humanos: Convenio Europeo para los Derechos y las Libertades Fundamentales (artículo 35.1) y TEDH. Asunto Vučković y otros $v$. Serbia, no 17153/11, sentencia de 25 de marzo de 2014, párrs. 69-91.

30 En este aspecto, la jurisprudencia de la Corte Interamericana es muy cercana a la del Tribunal Europeo de Derechos Humanos sobre la misma materia. Vid. SPANO, Robert. "Universality or Diversity of Human Rights? Strasbourg in the Age of Subsidiarity". Human Rights Law Review, v. 14, n. 3, p. 500.

31 CORTE IDH. Excepciones al agotamiento de los recursos internos (Arts. 46.1, 46.2. a y 46.2.b, Convención Americana sobre Derechos Humanos). Opinión Consultiva OC-11/90 de 10 de agosto de 1990. Serie A No. 11, párrs. 32 y 35. Algunos casos difíciles sobre el cumplimiento del requisito de agotamiento de los recursos internos en: Pasqualucci, Jo M. The Practice and Procedure of the Inter-American Court of Human Rights. Cambridge University Press, Cambridge, 2013, pp. 97-98.

32 CORTE IDH. Caso Cantoral Benavides Vs. Perú. Excepciones Preliminares. Sentencia de 3 de septiembre de 1998. Serie C No. 40, párr. 31.

33 El Estado no puede alegar la falta de agotamiento de los recursos internos cuando la violación a los derechos humanos constituye un delito que debe ser investigado y sancionado de oficio por las autoridades nacionales (i.e. desaparición forzada). TOJO, Liliana; ELIZALDE, Pilar. "Competencia de la Comisión Interamericana de Derechos Humanos". En: STEINER, Christian; URIBE, Patricia. (Ed.). Convención Americana sobre Derechos Humanos. Comentario. Bogotá: Temis-Konrad Adenauer Stiftung, 2014. p. 779. 
ante la Comisión ${ }^{34}$. Esta carga de diligencia evita que los Estados utilicen este argumento como una defensa tardía cuando el proceso se encuentra en una etapa avanzada, cuando se han formulado las consideraciones de fondo por parte de la Comisión o cuando el caso ya ha sido deferido a la Corte ${ }^{35}$.

Del mismo modo, cuando el Estado presenta la excepción preliminar ante la Comisión y esta es rechazada, el Estado puede insistir en el mismo argumento ante la Corte con el fin de que el tribunal revise si la CIDH decidió la excepción con información completa y veraz ${ }^{36}$. Esta posibilidad ha generado críticas porque implica una dilación y la duplicidad de los procedimientos. Sin embargo, se ha mantenido bajo el criterio de que la Corte Interamericana no reexamina totalmente la excepción preliminar, sino que verifica que la Comisión la haya resuelto con todos los elementos de juicio necesarios ${ }^{37}$. Adicionalmente, la intervención de la Corte en el control de legalidad de una actuación realizada por la Comisión está orientada por la necesidad de garantizar el derecho de defensa de las partes del proceso interamericano ${ }^{38}$.

Desde luego, las víctimas de una violación a los derechos humanos no deben agotar los recursos internos cuando estos no satisfacen los requisitos de idoneidad establecidos por la Corte Interamericana. Además, el artículo 46.2 de la Convención y 31.2 del Reglamento de la Comisión establecen tres excepciones al deber de agotamiento de los recursos internos.

Por una parte, no se puede exigir a la víctima que agote un recurso interno cuando este no ofrece garantías suficientes en el marco del debido proceso. En segundo lugar, tampoco se aplica la regla del agotamiento de los recursos internos cuando la víctima aduce precisamente la violación de su derecho a un recurso efectivo en virtud de que se le impidió materialmente acceder al sistema judicial nacional. En tercer lugar, la regla del agotamiento de los recursos internos no es exigible cuando existe una dilación injustificada de los procedimientos internos que debían ser agotados, de manera tal, que se ha producido un incumplimiento del plazo razonable ${ }^{39}$.

En este ámbito opera una carga dinámica de la prueba que funciona de la siguiente manera. Si el peticionario aduce que no debía agotar los recursos internos porque concurría una de las excepciones, el Estado asume la carga de probar que los recursos existían, se encontraban disponibles, eran adecuados y efectivos ${ }^{40}$. En cualquiera de los dos casos, tanto el requisito de agotamiento de los recursos internos como sus excepciones deben ser interpretados a favor de las víctimas ${ }^{41}$.

La regla del agotamiento de los recursos internos es un mecanismo de subsidiariedad establecido a favor de los Estados, "pues busca dispensarlo de responder ante un órgano internacional por actos que se le

34 CORTE IDH. Caso Brewer Carías Vs. Venezuela. Excepciones Preliminares. Sentencia de 26 de mayo de 2014. Serie C No. 278 , párr. 77. 35 CORTE IDH. Caso Herrera Ulloa V s. Costa Rica. Excepciones Preliminares, Fondo, Reparaciones y Costas. Sentencia de 2 de julio de 2004. Serie C No. 107, párr. 81. Sobre la estrategia de litigio de los Estados mediante la utilización tardía de la excepción preliminar de falta de agotamiento de los recursos internos: Burgorgue-Larsen, Laurence; ÚBEDA DE TORRES, Amaya. The InterAmerican Court of Human Rights. Case Law and Commentary. Oxford: Oxford University Press, 2011. p. 132-136.

36 Hasta el momento, el único proceso en el que la excepción del agotamiento de los recursos internos ha prosperado cuando el caso ya se encontraba bajo el conocimiento de la Corte Interamericana fue: CORTE IDH. Caso Brewer Carías Vs. Venezuela. Excepciones Preliminares. Sentencia de 26 de mayo de 2014. Serie C No. 278, párr. 144.

37 PASQUALUCCI, Jo M. The Practice and Procedure of the Inter-American Court of Human Rights. Cambridge: Cambridge University Press, 2013. p. 94.

38 CORTE IDH. Caso Brewer Carías Vs. Venezuela. Excepciones Preliminares. Sentencia de 26 de mayo de 2014. Serie C No. 278, párr. 102.

39 La Corte Interamericana ha diseñado un test para evaluar la posible existencia de dilaciones injustificadas y la resolución de los recursos internos dentro de un plazo razonable en los términos del artículo 8.1. de la Convención. De acuerdo con el Tribunal Interamericano, el plazo razonable varía en función de cuatro criterios: i) la complejidad del asunto, ii) la actividad probatoria y el interés del afectado, iii) la conducta de las autoridades judiciales y iv) el impacto sobre los derechos de los peticionarios derivado de su situación jurídica. Vid. CORTE IDH. Caso Valle Jaramillo y otros Vs. Colombia. Fondo, Reparaciones y Costas. Sentencia de 27 de noviembre de 2008. Serie C No. 192, párr. 155.

40 CORTE IDH. Caso Brewer Carías Vs. Venezuela. Excepciones Preliminares. Sentencia de 26 de mayo de 2014. Serie C No. 278, párr. 84.

41 Burgorgue-Larsen, Laurence; ÚBEDA DE TORRES, Amaya. The Inter-American Court of Human Rights. Case Law and Commentary. Oxford: Oxford University Press, 2011. p. 138-143. 
imputen, antes de haber tenido la ocasión de remediarlos con sus propios medios" ${ }^{\prime 2}$. De esa consideración se deriva que se trata de un beneficio renunciable expresamente cuando los Estados así lo señalan o tácitamente cuando no se invoca la excepción preliminar de manera oportuna ${ }^{43}$.

\subsection{La mal denominada fórmula de la cuarta instancia}

El segundo mecanismo de subsidiariedad que opera en el ámbito del Sistema Interamericano es la incorrectamente denominada fórmula o regla de la cuarta instancia. Esta tiene el objetivo de evitar que los tribunales internacionales se erijan en una instancia más de revisión de los errores procesales, probatorios o de interpretación en que pueden incurrir los jueces domésticos ${ }^{44}$.

Esta fórmula se aplica cuando una petición individual solicita que los órganos del Sistema Interamericano revisen la manera como los jueces nacionales valoraron el material probatorio o interpretaron y aplicaron el derecho interno ${ }^{45}$. Según la propia Corte Interamericana, esa institución "no es, por tanto, un tribunal de alzada o de apelación para dirimir los desacuerdos que tengan las partes sobre determinados alcances de la prueba o de la aplicación del derecho interno en aspectos que no estén directamente relacionados con el cumplimiento de obligaciones internacionales en derechos humanos" ${ }^{\prime 46}$.

La fórmula de la cuarta instancia establece que la mera inconformidad con las decisiones judiciales de las instancias nacionales no es un fundamento suficiente para buscar la protección de una pretensión ante los órganos del Sistema Interamericano. En consecuencia, se puede haber agotado los recursos internos y obtenido una decisión judicial desfavorable a las pretensiones y, ese hecho por sí solo, no justifica la intervención de los órganos del Sistema Interamericano. La idea central es que la protección internacional no es una instancia más a la que se puede acudir para revisar o corregir las decisiones de los jueces nacionales.

En definitiva -y más allá de su incorrecta denominación- la fórmula de la cuarta instancia evita la intervención de la Corte Interamericana para lograr la perfectibilidad de los sistemas judiciales nacionales o el mejoramiento de sus métodos de investigación, juzgamiento o decisión ${ }^{47}$. En consecuencia, no existe ninguna razón para pensar que el derecho de acceso a la jurisdicción interamericana es una especie de recurso de apelación de las decisiones judiciales nacionales o que representa una ruptura de la idea de unos tribunales de cierre dentro de los ordenamientos jurídicos nacionales.

\subsection{El margen de apreciación nacional}

A diferencia de los dos anteriores mecanismos de subsidiariedad, el margen de apreciación nacional es un instrumento de deferencia. Se trata de una herramienta propia del sistema Europeo de Derechos Humanos ${ }^{48}$

42 CORTE IDH. Caso Duque Vs. Colombia. Excepciones Preliminares, Fondo, Reparaciones y Costas. Sentencia de 26 de febrero de 2016. Serie C No. 310, párr. 35.

43 CORTE IDH. Caso Brewer Carias Vs. Venezuela. Excepciones Preliminares. Sentencia de 26 de mayo de 2014. Serie C No. 278 , párr. 57. 44 NEUMAN, Gerald. "Subsidiarity". En: SHELTON, Dinah (Ed.). The Oxford Handbook of International Human Rights Law. Oxford: Oxford University Press, 2013. p. 372.

45 DUHAIME, Bernard. "Subsidiarity in the Americas. What room is there for deference in the Inter-American System? ”. En: GRUSZCZYNSKI, Lukasz; WERNER, Wouter. Deference in International Courts and Tribunals. Oxford: Oxford University Press, 2014. p. 291 y 292.

46 CORTE IDH. Caso González. Medina y familiares Vs. República Dominicana. Excepciones Preliminares, Fondo, Reparaciones y Costas. Sentencia de 27 de febrero de 2012. Serie C No. 240, párr. 38.

47 "La Corte recuerda que corresponde a los tribunales del Estado el examen de los hechos y las pruebas presentadas en las causas particulares. No compete a este Tribunal sustituir a la jurisdicción interna estableciendo las modalidades específicas de investigación y juzgamiento en un caso concreto para obtener un mejor o más eficaz resultado, sino constatar si en los pasos efectivamente dados a nivel interno se violaron o no obligaciones internacionales del Estado derivadas de los artículos 8 y 25 de la Convención americana". CORTE IDH. Caso Nogueira de Carvalho y otro Vs. Brasil. Excepciones Preliminares y Fondo. Sentencia de 28 de noviembre de 2006. Serie C No. 161, párr. 80.

48 Algunos elementos del margen de apreciación nacional también han sido aplicados en el derecho internacional de las inversiones 
que apareció por primera vez en informes de la extinta Comisión Europea de Derechos Humanos desde el año $1958^{49}$ y que ha sido aplicada por el Tribunal Europeo desde el asunto Handyside v. Reino Unido en el año $1976^{50}$. Se trata de un reconocimiento de que los Estados tienen condiciones y circunstancias especiales que justifican diferentes maneras de cumplir con sus obligaciones internacionales y de garantizar los derechos establecidos en el Convenio ${ }^{51}$.

Yourow lo definió como una libertad de actuar, un margen de autonomía o un espacio discrecional que el Tribunal Europeo confiere a las autoridades domésticas para restringir o limitar un derecho establecido en el Convenio ${ }^{52}$. Por su parte, Samantha Besson señala que el margen de apreciación es una herramienta que "reconoce la existencia de una variedad de interpretaciones diferentes pero justificadas del derecho internacional de los derechos humanos que dependen del contexto doméstico" 53 .

Desde una visión positiva, el margen de apreciación nacional reconoce que los derechos protegidos por el Convenio pueden ser efectivamente garantizados por los Estados de diferentes maneras de acuerdo con sus particulares condiciones y contextos ${ }^{54}$. Como señalan Mowbray y MATTHEw, el margen de apreciación nacional establece un criterio de deferencia con las decisiones de las autoridades políticas y judiciales nacionales ${ }^{55}$ que consulta aspectos como la legitimidad democrática de las instituciones nacionales, su mejor posición funcional para evaluar las necesidades y condiciones locales y la calidad de sus procedimientos ${ }^{56}$. Según algunos estudios, el margen de apreciación nacional se ha aplicado en más de 700 sentencias del Tribunal Europeo de Derechos Humanos ${ }^{57}$.

Desde el año 2013, el Consejo de Europa ha iniciado un proceso para reelaborar y fortalecer el concepto de subsidiariedad y de deferencia de la jurisdicción del Tribunal Europeo de Derechos Humanos. Uno de los aspectos esenciales de ese proceso es el Protocolo xv al Convenio Europeo de Derechos Humanos. En este Protocolo se adiciona un párrafo final al Preámbulo del Convenio en el que se hace referencia expresa a la subsidiariedad y al margen de apreciación nacional en los siguientes términos:

"Afirmando que las Altas Partes Contratantes, de conformidad con el principio de subsidiariedad, tienen la responsabilidad primordial de garantizar los derechos y las libertades establecidas en el presente Convenio y sus Protocolos y que, al hacerlo, gozan de un margen de apreciación sujeto a la supervisión

y por parte de la Corte Internacional de Justicia. Vid. LEONHARDSEN, Erlend. "Treaty Change, Arbitral Practice and the Search for a Balance: Standards of Review and the Margin of Appreciation in International Investment Law”. En: GRUSZCZYNSKI, Lukasz; WERNER, Wouter. Deference in International Courts and Tribunals. Oxford: Oxford University Press, 2014. p. 135-151. RAGNI, Chiara. "Standard of Review and the Margin of Appreciation before the International Court of Justice". En: GRUSZCZYNSKI, Lukasz; WERNER, Wouter. Deference in International Courts and Tribunals. Oxford: Oxford University Press, 2014. p. 319-336.

49 GREER, Steven. "The margin of appreciation: interpretation and discretion under the European Convention of Human Rights”. Human Rights Files, n. 17, p. 5, Consejo de Europa, Estrasburgo, 2010 y GARCÍA ROCA, Javier. El margen de apreciación nacional en la interpretación del Convenio Europeo de Derechos Humanos: soberanía e integración. España: Thomson Reuters-Civitas, 2010. p. 107-112.

50 TEDH. Asunto Handyside v. Reino Unido, n 5493/72, sentencia del 7 diciembre de 1976, párrs. 48, 49 y 54.

51 Arai-Takahashi, Yutaka. The margin of appreciation doctrine and the principle of proportionality in the jurisprudence of the ECHR. Intersentia, Antwerp, 2002. p. 1-2.

52 YOUROW, Howard Charles. The margin of appreciation doctrine in the dynamics of European Human Rights jurisprudence. The Hague: Kluwer Law International, 1996. p. 13

53 Besson, Samantha. "Subsidiarity in International Human Rights Law — What Is Subsidiary about Human Rights?". The American Journal of Jurisprudence, v. 61, n. 1, p. 81, 2016.

54 Ambrus, Mónika. "The European Court of Human Rights and Standars of Proof: An evidential approach toward the margin of appreciation”. En: GRUSZCZYNSKI, Lukasz; WERNER, Wouter. Deference in International Courts and Tribunals. Oxford: Oxford University Press, 2014. p. 236.

55 Sobre la aplicación del principio de subsidiariedad en el ámbito del Tribunal Europeo de Derechos Humanos con información estadística acerca de las referencias al principio de subsidiariedad en las decisiones del tribunal desde el año 1992 hasta el año 2014 : MOWBRAY, Alastair. "Subsidiarity and the European Convention on Human Rights". Human Rights Law Review, v. 15, n. 2, p. 313-341, 2015.

56 SAUL, Matthew. "The European Court of Human Rights' Margin of Appreciation and the Processes of National Parliaments". Human Rights Law Review, v. 15, n. 4, p. 772, 2015.

57 GREER, Steven. "The margin of appreciation: interpretation and discretion under the European Convention of Human Rights”. Human Rights Files, n. 17, p. 5, Consejo de Europa, Estrasburgo, 2010. 
por parte de la jurisdicción del Tribunal Europeo de Derechos Humanos establecido por el presente Convenio" 58 .

Esta reforma al Preámbulo del Convenio ha generado lecturas contradictorias. Para algunos autores, se trata de una modificación menor que no introduce nada que ya no se encontrara incorporado en la jurisprudencia del tribunal. Para otros, esta adenda aumentará la relevancia del margen de apreciación nacional dentro de las deliberaciones del Tribunal Europeo ${ }^{59}$.

La reforma mencionada tiene una causa estructural y una causa política. La primera está relacionada con el aumento del número de casos que llegan al Tribunal Europeo y con la necesidad de que el remedio a las violaciones a los derechos humanos sea ordenado por las autoridades nacionales de los Estados miembros (reclamo de subsidiariedad). La segunda tiene que ver con el aumento de la tensión entre el Tribunal Europeo y algunos Estados que critican el activismo y la invasión de las competencias propias de sus autoridades nacionales por parte de los jueces de Estrasburgo (reclamo de deferencia) ${ }^{60}$.

Además del Protocolo xv, la propia jurisprudencia del Tribunal Europeo sobre el margen de apreciación nacional ha aumentado el enfoque de deferencia con los Estados. En ese ámbito, por ejemplo, el tribunal ha establecido que la calidad del proceso legislativo interno es un criterio relevante para examinar el grado de deferencia que debe tener el tribunal cuando evalúa una medida legislativa que limita el contenido o el ejercicio de un derecho establecido en el Convenio ${ }^{61}$. También es muy relevante la calidad de los procesos judiciales internos que revisan las medidas legislativas o administrativas que limitan los derechos establecidos en el Convenio ${ }^{62}$. Todos estos factores han llevado a que RoBert Spano señale que "la siguiente fase en la vida de la Corte de Estrasburgo puede ser definida como la era de la subsidiariedad, una fase en la cual se manifestará el compromiso del tribunal con el empoderamiento de los Estados Miembros para que estos verdaderamente 'traigan los derechos a casa', no solo en el Reino Unido sino en toda Europa" ${ }^{\text {. }}$.

En el marco del Sistema Interamericano no existe una jurisprudencia consolidada sobre el margen de apreciación nacional ${ }^{64}$. Sin embargo, según algunos autores, la Corte Interamericana aplicó expresamente el margen de apreciación nacional en la Opinión Consultiva 4 de $1984^{65}$ y en el caso Barreto Leiva v. Venezuela de

58 Vid. Protocolo xv reformatorio del Convenio Europeo para la Protección de los Derechos Humanos y las Libertades Fundamentales (artículo 1). La reforma del Protocolo fue abierta a la firma de los Estados el 24 de junio de 2013.

59 SAUL, Matthew. "The European Court of Human Rights' Margin of Appreciation and the Processes of National Parliaments". Human Rights Law Review, v. 15, n. 4, p. 749, 2015, y Besson, Samantha. "Subsidiarity in International Human Rights Law — What Is Subsidiary about Human Rights?”. The American Journal of Jurisprudence, v. 61, n. 1, p. 60--61, 2016.

60 Las críticas por el activismo judicial del Tribunal Europeo de Derechos Humanos aparecen resumidas y contestadas en: SPANO, Robert. "Universality or Diversity of Human Rights? Strasbourg in the Age of Subsidiarity". Human Rights Law Review, v. 14, n. 3, p. 488-502. 61 TEDH. Asunto Animal Defenders International v United Kingdom, n 48876/08, sentencia de 22 de abril de 2013, párr. 108. Los criterios con los cuales el Tribunal Europeo evalúa los procedimientos legislativos nacionales han sido resumidos en: SAUL, Matthew. "The European Court of Human Rights' Margin of Appreciation and the Processes of National Parliaments". Human Rights Law Review, v. 15, n. 4, p. 753-767, 2015.

62 SPANO, Robert. "Universality or Diversity of Human Rights? Strasbourg in the Age of Subsidiarity". Human Rights Law Review, v. 14, n. 3, p. 499-502.

63 SPANO, Robert. "Universality or Diversity of Human Rights? Strasbourg in the Age of Subsidiarity”. Human Rights Law Review, v. 14, n. 3, p. 491.

64 Algunos ejemplos de aplicación del margen de apreciación nacional por parte de la Comisión Interamericana de Derechos Humanos en: DUHAIME, Bernard. "Subsidiarity in the Americas. What room is there for deference in the Inter-American System?”. En: GRUSZCZYNSKI, Lukasz; WERNER, Wouter. Deference in International Courts and Tribunals. Oxford: Oxford University Press, 2014. p. 303-308. Para un análisis de los casos en los cuales se ha solicitado a la Corte Interamericana que aplique el margen de apreciación nacional y la recepción de esos argumentos por parte del Tribunal Interamericano, se sugiere consultar los trabajos compilados en: Acosta Alvarado, Paola Andrea; Nuñez Poblete, Manuel. El margen de apreciación en el sistema interamericano de derechos bumanos: proyecciones regionales y nacionales. México: IIJ-UNAM, 2012. p. 3-381.

65 Se hace referencia al margen de apreciación que la Corte Interamericana reconoció al Estado de Costa Rica en relación con la garantía efectiva del derecho a la nacionalidad (artículo 20 de la Convención) mediante el establecimiento de una serie de requisitos para adquirir la nacionalidad de ese país. Vid. CORTE IDH. Propuesta de modificación a la Constitución Política de Costa Rica relacionada con la naturalización. Opinión Consultiva OC-4/84 de 19 de enero de 1984. Serie A No. 4, párrs. 58, 59, 62 y 63. La tesis según la cual en esta Opinión Consultiva se aplicó el margen de apreciación se puede encontrar en: Arai-Takahashi, Yutaka. The margin of appreciation doctrine and the principle of proportionality in the jurisprudence of the ECHR. Intersentia, Antwerp, 2002. p. 4. 
$2009^{66}$ e implícitamente en el caso Herrera Ulloa v. Costa Rica de $2004^{67}$.

No obstante estos tres ejemplos concretos de potencial aplicación del margen de apreciación nacional, es importante señalar que, en el caso Artavia Murillo v. Costa Rica de 2012, la Corte Interamericana omitió pronunciarse sobre los argumentos del Estado que solicitaba expresamente el reconocimiento de un margen de apreciación nacional sobre la regulación de la técnica de reproducción asistida, denominada fecundación in vitro. El tribunal consideró que, una vez comprobado el carácter desproporcionado de la medida interna, no era necesario pronunciarse respecto al reclamo del Estado sobre el margen de apreciación nacional ${ }^{68}$.

Aun así, los primeros brotes del margen de apreciación nacional en el marco del Sistema Interamericano han sido considerados como un resultado de la consolidación democrática de los Estados de la región que ha llevado al Tribunal Interamericano a ampliar su agenda para intervenir en casos sobre temas más cotidianos. En ese contexto, habría surgido nuevamente una preocupación por el grado de intervención de los órganos internacionales en los asuntos de los Estados ${ }^{69}$, un reclamo por la adopción de enfoques de deferencia y una tendencia a aceptar una versión más fuerte del principio de subsidiariedad ${ }^{70}$.

La anterior explicación es seductora pero bastante optimista. Si bien es cierto que la agenda de la Corte Interamericana se ha ampliado y que existe una aparente consolidación de la democracia y del Estado de Derecho en la mayor parte de los países de la región, también es importante reconocer las deficiencias estructurales que se mantienen incólumes en relación con la garantía efectiva de los derechos humanos más básicos, los déficits de las judicaturas nacionales para responder a las demandas masivas de acceso a la justicia y los nuevos peligros para la democracia y el Estado de Derecho derivados de la extensión de los regímenes de presidencialismo exacerbado. Como lo ha señalado AIDA TORRES, algunas de estas amenazas se extienden hacia la propia independencia de la Corte Interamericana de Derechos Humanos debido a la alta influencia de los Gobiernos nacionales en el nombramiento de los jueces de ese tribunal, a la generalidad de los requisitos para ser juez de la Corte Interamericana, al déficit de transparencia de los procesos de elección y a la práctica de intercambio de votos entre los Gobiernos latinoamericanos para la elección de los diferentes cargos internacionales ${ }^{71}$. En todos estos ámbitos, América Latina todavía se encuentra muy lejos de los parámetros europeos que permiten la deferencia del tribunal de Estrasburgo con los Estados del Consejo de Europa.

En ese contexto, la Corte Interamericana debe restringir el ámbito de aplicación de esta herramienta europea o descartarla completamente, por lo menos, hasta tanto los Estados que se encuentran bajo su jurisdicción no demuestren que satisfacen plenamente el fundamento democrático que justifica la deferencia del

66 CORTE IDH. Caso Barreto Leiva Vs. Venezuela. Fondo, Reparaciones y Costas. Sentencia de 17 de noviembre de 2009. Serie C No. 206, párr. 90. La tesis según la cual en este caso se aplicó el margen de apreciación se puede encontrar en: SAGÜÉS, Néstor Pedro. La Constitución bajo tensión. México: Instituto de Estudios Constitucionales del Estado de Querétaro, 2016. p. 392.

67 CORTE IDH. Caso Herrera Ulloa Vs. Costa Rica. Excepciones Preliminares, Fondo, Reparaciones y Costas. Sentencia de 2 de julio de 2004. Serie C No. 107, párr. 161. La tesis según la cual en este caso se aplicó el margen de apreciación se puede encontrar en: CONTRERAS, Pablo. "Control de convencionalidad, deferencia internacional y discreción nacional en la jurisprudencia de la Corte Interamericana de Derechos Humanos". Revista Ius et Praxis, v. 20, n. 2, p. 242-243, 2014.

68 El Estado de Costa Rica solicitó el reconocimiento de un margen de apreciación nacional en relación con la regulación de la técnica de reproducción asistida, denominada fecundación in vitro, sobre la base de la inexistencia de un consenso científico y regional sobre momento del inicio de la vida humana, el estatuto jurídico del embrión y la regulación de esa técnica de reproducción. La Corte Interamericana señaló que no era pertinente pronunciarse sobre ese tipo de argumentos porque ya se había comprobado el carácter desproporcionado de la medida nacional que limitaba el uso de la fecundación in vitro. Vid. CORTE IDH. Caso Artavia Murillo y otros ("Fecundación in vitro") Vs. Costa Rica. Excepciones Preliminares, Fondo, Reparaciones y Costas. Sentencia de 28 noviembre de 2012. Serie C No. 257, párrs. 170 y 316.

69 CORTE SUPREMA DE JUSTICIA DE LA NACIÓN ARGENTINA. Sentencia de 14 de febrero de 2017. CSJ368/1998 34 M)/CS1. Ministerio de Relaciones Exteriores y Cultos/informe sentencia dictada en el caso "Fontevecchia y D'Amico vs. Argentina" por la Corte Interamericana de Derechos Humanos.

70 FOLLESDAL, Andreas. "Exporting the margin of appreciation: Lessons for the Inter-American Court of Human Rights". International Journal of Constitutional Law, v. 15, n. 2, p. 359-371, 2017.

71 TORRES PÉREZ, Aida. "La independencia de la Corte Interamericana de Derechos Humanos desde una perspectiva institucional”. En: IGLESIAS VILA, Marisa et al. Derechos Humanos: posibilidades teóricas y desafíos prácticos. Buenos Aires: Libraria, 2014. p. 66-88. 
sistema internacional con los procedimientos legislativos y judiciales internos, y hasta tanto no se fortalezcan los mecanismos judiciales internos y las garantías de independencia para las judicaturas nacionales a fin de considerar que estas se encuentran en una mejor posición funcional que el propio tribunal de San José ${ }^{72}$. Hasta el momento, muchas de las decisiones contenciosas de la Corte Interamericana constituyen la verdad judicial sobre casos de violaciones a los derechos humanos y estas contrastan con las dilaciones o con los modestos resultados de los procesos judiciales internos en esos mismos casos ${ }^{73}$.

\subsection{Enfoques de deferencia como alternativa al margen de apreciación nacional}

El rechazo a la aplicación del margen de apreciación nacional en el ámbito del SIDH no quiere decir que la Corte IDH deba ser insensible a consideraciones contextuales y a argumentos relacionados con las condiciones específicas de cada uno de los Estados. No se trata de un margen de apreciación sino del análisis concreto que supone la existencia de un caso contencioso que ha ocurrido en un Estado determinado, dentro de unas condiciones acotadas y en un marco fáctico preciso.

Eso significa que es posible aplicar enfoques de deferencia y contextuales sin necesidad de llegar al extremo de reconocer un margen de apreciación nacional. La deferencia implica analizar la calidad democrática de las decisiones legislativas adoptadas por los parlamentos nacionales, el grado de deliberación social sobre decisiones que han resuelto un desacuerdo dentro de un Estado, los atributos de los procedimientos judiciales internos, el grado de apertura a la ciudadanía de los foros políticos y judiciales, y la actitud de las autoridades nacionales hacia la apertura y el diálogo con los estándares fijados por los tribunales internacionales.

De manera que los esfuerzos probados, reiterados, constantes y productivos de las instancias nacionales para aplicar, implementar y adaptar sus normas y prácticas internas a los estándares interamericanos son parámetros relevantes para aplicar un enfoque de deferencia. Esos criterios le permiten identificar a la Corte IDH cuando se encuentra dentro de un proceso dialéctico y deliberativo genuino con las autoridades nacionales. Ese proceso ocurre cuando ambas instancias se hallan dentro de un foro en el que ocurre una discusión respetuosa, cada una de las partes toma con la mayor seriedad y respeto la mejor versión de los argumentos de la otra y tiene toda la disposición para modificar su posición inicial frente a un argumento cualificado contrario a su punto de partida.

Desde luego, en ese diálogo institucional tiene que existir una definición. Se trata de una especie de última palabra, que será siempre provisional en la medida en que los estándares interamericanos pueden cambiar y las prácticas nacionales pueden variar. Eso significa que la ampliación de las herramientas de deferencia de los tribunales internacionales con las autoridades nacionales debe estar precedida de un análisis sobre la calidad de los recursos internos y los mecanismos procesales domésticos para graduar la intensidad del escrutinio que realizan los tribunales internacionales respecto de las actuaciones de las autoridades nacionales. Dicho de otra manera, la legitimidad de los procedimientos legislativos, judiciales y administrativos internos y la calidad de los mismos permite determinar si debe existir una mayor intervención o deferencia de parte de los tribunales internacionales.

Desde el SIDH se pueden asumir enfoques deferentes o de intervención, según corresponda, a manera de reconocimiento, estímulo y presión para que los Estados mejoren progresivamente sus sistemas judi-

72 Una crítica a los sistemas judiciales nacionales como argumento para evaluar el grado de subsidiariedad del Sistema Interamericano de Derechos Humanos: KLETZEL, Gabriela et al. "Democracia y subsidiariedad". En: BARRETO MAIA, Camila et al. Desafíos del Sistema Interamericano de Derechos Humanos. Nuevos tiempos, viejos retos. Bogotá: DeJusticia, 2015. p. 191-228.

73 CORTE IDH. Caso de la "Masacre de Mapiripán" Vs. Colombia. Sentencia de 15 de septiembre de 2005. Serie C No. 134 y Corte IDH. Caso Rodríguez. Vera y otros (Desaparecidos del Palacio de Justicia) Vs. Colombia. Excepciones Preliminares, Fondo, Reparaciones y Costas. Sentencia de 14 de noviembre de 2014. Serie C No. 287. Un diagnóstico en este sentido: ACOSTA ALVARADO, Paola Andrea. "Los casos colombianos ante el sistema interamericano y el uso del margen de apreciación: ¿ausencia justificada?". En: ACOSTA ALVARADO, Paola Andrea; NUÑEZ POBLETE, Manuel. El margen de apreciación en el Sistema Interamericano de Derechos Humanos: Proyecciones Regionales y Nacionales. Universidad Nacional Autónoma de México, 2012. p. 183-238. 
ciales, administrativos y disciplinarios internos. Según este punto de vista, la cualificación de los sistemas internos de protección de los derechos también es una contribución central al mejor funcionamiento del SIDH porque reduce el número de casos que se pueden incluir dentro de las competencias de los tribunales internacionales, se reduce la carga de trabajo dentro de esas instancias y permite que la jurisdicción internacional se concentre en diversos temas de la agenda de protección de los derechos humanos.

Con base en todo lo anterior, en la siguiente sección se defenderá que es plausible considerar que los procedimientos sancionatorios realizados por la Procuraduría General de la Nación de Colombia aplican materialmente las garantías judiciales establecidas en los artículos 8 y 25 de la CADH. Esa tesis permitirá avanzar en la búsqueda de una interpretación compatible de la CADH con las funciones de esa importante entidad del Estado colombiano mediante la aplicación de un criterio de deferencia mutua. Bajo ese parámetro, se mantendrá que la Corte IDH debe realizar un análisis integral y deferente de todo el procedimiento sancionatorio y del control judicial del mismo. Al mismo tiempo, la Procuraduría General de la Nación y las autoridades judiciales internas deben optimizar el nivel de satisfacción de todas las garantías judiciales para obtener el máximo respeto a los derechos políticos -tanto de los electores como los elegidos- en el marco de los procesos sancionatorios que se adelantan contra funcionarios elegidos popularmente.

\section{UNA INTERPRETACIÓN COMPATIBLE DE LA CADH CON LAS FUNCIONES DISCIPLINARIAS DE LAS AUTORIDADES ADMINISTRATIVAS BAJO EL ENFOQUE DE LA DEFERENCIA Y LA APLICACIÓN DEL DERECHO CONVENCIONAL}

El estándar de protección de los derechos políticos establecido en el caso López. Mendoza Vs. Venezuela tiene todas las fortalezas y todas las debilidades propias de una interpretación originalista textualista del artículo 23.2 de la CADH. Desde luego, parece una interpretación sólida porque la exigencia de que las limitaciones a los derechos políticos sean impuestas por un juez, con las garantías equivalentes a las del proceso penal y como consecuencia de un delito coincide plenamente con la intención original de los redactores de la CADH plasmada en las palabras utilizadas en ese instrumento internacional.

Sin embargo, la propia Corte IDH ha señalado que la CADH es un texto vivo que debe ser interpretado de manera evolutiva. Eso significa que es posible dejar atrás la idea de que solo las autoridades judiciales -y dentro de estas los jueces penales- aplican satisfactoriamente las garantías establecidas en el artículo 8 de la $\mathrm{CADH}$. Ese rezago interpretativo invitaba a penalizar determinadas conductas, no por la gravedad de las mismas, sino porque se consideraba que estas debían ser conocidas por los jueces penales que aplicaban parámetros procedimentales más exigentes. Una muestra de esa visión se encuentra detrás del estándar fijado en el caso López. Mendoza Vs. Venezuela. Por ejemplo, en el informe de fondo que la CIDH presentó a la Corte IDH en ese caso, la CIDH indicó lo siguiente:

[...] la imposición de una sanción de inhabilitación para la postulación a un cargo de elección popular, por un periodo de tiempo, tiene la naturaleza de sanción penal por lo que obliga a exigir, a quien tiene la facultad de imponerla, el respeto de ciertas garantías procesales propias de un procedimiento de índole penal, las cuales son más estrictas que las garantías del debido proceso que se exigen en los procedimientos administrativos ${ }^{74}$. (subrayado fuera de texto)

El presupuesto de la CIDH en ese informe es que el estándar de garantías judiciales aplicado por las autoridades administrativas es inferior al que aplica el juez penal. Por esa razón -bajo esa lógica- la única forma de garantizar que el proceso de inhabilitación de un funcionario público elegido popularmente satisfaga las garantías judiciales del artículo 8 de la CADH es restringir la facultad sancionatoria al juez penal. Este postulado contraría la propia jurisprudencia de la Corte IDH que ha indicado que las autoridades ad-

74 CIDH. Informe 92/09. Caso 12.668. Fondo, Leopoldo López Mendoza, Venezuela, 8 de agosto de 2009, párr. 91. 
ministrativas también deben aplicar las garantías judiciales pertinentes del artículo 8 de la CADH. Además, constituye una especie de falsa penalización tutelar en la que no se acota el universo de hechos que puede dar lugar a la inhabilidad o destitución, sino que se penalizan todas las faltas, incluso aquellas que por su levedad no ameritan un tratamiento punitivo.

Para avanzar en una interpretación material, evolutiva y sistemática de la CADH resulta pertinente formular la siguiente pregunta: ¿es legítimo que una autoridad administrativa sancione a un funcionario público elegido popularmente si esa autoridad aplica un estándar de garantías judiciales equivalente o superior al estándar que aplicaría el juez penal? Desde luego, eso habilitaría a las autoridades administrativas para destituir e inhabilitar funcionarios públicos elegidos popularmente y mantendría una distinción entre faltas disciplinarias y delitos.

La respuesta a esa pregunta es que una lectura material de las garantías exigidas por el artículo 23.2 de la CADH y por la jurisprudencia de la Corte IDH permite inferir que es plausible evaluar si una determinada autoridad administrativa aplica el estándar de garantías judiciales equivalente al del proceso penal cuando el procedimiento tiene por objetivo decidir sobre una sanción a un funcionario público elegido popularmente. Si esa evaluación es favorable a la autoridad que realiza el procedimiento sancionatorio, nada impide que la Corte IDH adopte un enfoque de deferencia y privilegie las garantías judiciales esenciales para la preservación de los derechos políticos sobre la nomenclatura o clasificación accidental de la autoridad que impone la sanción disciplinaria.

La anterior es una interpretación que confiere el mayor efecto útil a la CADH y a los estándares establecidos por la Corte IDH en materia de protección de los derechos políticos. Este efecto útil se obtiene sin vaciar de competencias a las autoridades disciplinarias internas y sin trastocar el complejo esquema nacional de responsabilidad disciplinaria. Asimismo, esta interpretación preserva una distinción entre faltas disciplinarias y delitos y evita la conversión en delitos de todas las faltas disciplinarias. En suma, se trata de una interpretación que encuentra el núcleo de la protección de los derechos políticos, tanto de los electores como de los elegidos, y lo centra en el conjunto de garantías que deben rodear el proceso que conduce a la destitución e inhabilitación de un funcionario público elegido popularmente.

Como se trata de una interpretación evolutiva de lege ferenda, a continuación se indicarán las condiciones de esa interpretación y las ventajas de la misma para los Estados, para el propio SIDH y para la satisfacción efectiva de los derechos políticos y las garantías judiciales, en el marco de los procesos que realizan las autoridades nacionales para perseguir y sancionar la corrupción.

\subsection{Las condiciones de la interpretación compatible: derechos políticos y garantías judiciales}

La interpretación evolutiva implica reconocer que el paso del tiempo produce una distancia inevitable entre el texto normativo y la realidad sobre la cual este debe operar. Desde luego, no se trata de que la realidad determine la eficacia de las normas sino de que estas sean aplicadas racionalmente y con base en elementos contextuales. El objetivo de la interpretación evolutiva es reducir la brecha intergeneracional que se crea entre la generación de quienes escriben y aprueban una norma y las generaciones posteriores. Además, la interpretación evolutiva aumenta la eficacia normativa y permite resolver conflictos o antinomias.

Desde luego, el solo paso del tiempo o el cambio generacional no justifican una interpretación evolutiva. Además, cuando este tipo de interpretación resulta razonable, es importante fijar el conjunto de condiciones que hacen plausible esa nueva interpretación. Por esa razón, en el caso de la antinomia entre la CADH y las funciones disciplinarias de la Procuraduría General de la Nación, la condición compleja esencial es la deferencia mutua. Eso implica que, tanto la CIDH y la Corte IDH como los órganos (judiciales y administrativos) internos, deben tomar con seriedad la posición de la CADH, la interpretación de la misma y las condiciones institucionales y contextuales en que esta opera en el caso de los procedimientos disciplinarios que realiza la Procuraduría General de la Nación contra funcionarios públicos elegidos popularmente. 
Desde el punto de vista del Estado, la condición compleja para que la interpretación sugerida en esta investigación sea plausible consiste en que se implementen las recomendaciones formuladas por la CIDH con el fin de adecuar, al máximo posible, el ordenamiento jurídico interno a los estándares interamericanos sobre los artículos 8, 23 y 25 de la CADH. Como ya ha sido establecido expresamente por la CIDH, eso implica que se expidan las normas necesarias para: i) asegurar la imparcialidad de la autoridad disciplinaria al distinguir las autoridades encargadas de formular los cargos de aquellas que deciden de fondo sobre la responsabilidad disciplinaria, ii) asegurar la accesibilidad y efectividad de los recursos contra las decisiones disciplinarias, iii) asegurar que los recursos contra las decisiones disciplinarias permitan una revisión integral de esas decisiones y iv) asegurar que todas las acciones de nulidad y restablecimiento del derecho serán decididas dentro de un plazo razonable ${ }^{75}$.

Desde la perspectiva de la CIDH y la Corte IDH, la condición de plausibilidad de esta interpretación pasa por el reconocimiento de que la interpretación vigente (lege lata) ofrece una protección aparente, formal y textual de los derechos establecidos en el artículo 23 de la CADH. Asimismo, los órganos del SIDH deben examinar el contexto concreto de cada autoridad nacional que ejerce funciones disciplinarias respecto de funcionarios públicos elegidos popularmente y la calidad convencional de sus procedimientos. Desde luego, es importante que la Corte IDH interprete todas las normas internacionales relevantes que incluyen deberes de los Estados en materia de persecución y sanción de la corrupción y asuma un enfoque más amplio relacionado con el impacto de la corrupción en la garantía efectiva de los derechos económicos, sociales, culturales y ambientales (DESCA). Además, la CIDH y la Corte IDH deben promover el diálogo institucional con las autoridades nacionales que realizan procedimientos disciplinarios contra funcionarios públicos.

En el caso concreto de la Procuraduría General de la Nación, los órganos del SIDH deben reconocer que existe actualmente un diálogo institucional en el que el órgano nacional ha demostrado una apertura absoluta a los parámetros convencionales que orientan los procedimientos judiciales y administrativos. Dentro de ese diálogo, la Procuraduría General de la Nación ha iniciado proyectos de difusión del derecho convencional, una revisión crítica y en clave constructiva del procedimiento disciplinario y ha convertido en una prioridad el respeto de los derechos políticos de conformidad con el estándar interamericano. Poner punto final de manera prematura a ese diálogo con la simple reiteración del precedente López Mendoza Vs. Venezuela constituiría una pérdida de oportunidad institucional para avanzar en la protección convencional de las garantías judiciales, los derechos políticos, la lucha contra la corrupción y la protección de los DESCA en América Latina.

Finalmente, es importante señalar que no existe una obligación de deferencia en el SIDH. La deferencia es el resultado razonable y espontáneo de los esfuerzos institucionales mutuos, compartidos y probados por aumentar la protección de los derechos humanos en un caso concreto. Eso significa que la deferencia no se exige ni se concede. Como mucho, la deferencia puede ser provocada con acciones de apertura unilaterales que abren paso a la deliberación inter-institucional. En cualquier caso, la carga de la prueba opera sobre la institución que reclama la deferencia y existen buenas razones para considerar que la Procuraduría General de la Nación de Colombia ha abierto ese espacio de deliberación con los órganos del SIDH.

\subsection{A modo de conclusión. Las ventajas de la interpretación compatible: diálogo, deferencia, legitimidad y eficacia no contenciosa del sistema interamericano}

La interpretación de lege ferenda propuesta en esta investigación tiene varias ventajas institucionales y para la protección efectiva de los derechos humanos, especialmente, para las garantías judiciales, el acceso a un recurso efectivo y los derechos políticos. La primera de esas ventajas institucionales es que esta interpretación es el resultado de un diálogo o deliberación institucional entre los órganos del SIDH y las autoridades

75 Estas modificaciones corresponden a las ordenadas por la CIDH en: CIDH. Informe de Fondo No. 130/17. Caso 13.044. Gustavo Francisco Petro Urrego. 25 de octubre de 2017, párr. 149. 
internas. Desde luego, no se trata de un culto ciego a la deliberación como procedimiento para resolver desacuerdos sociales o normativos, sino del aprovechamiento de las ventajas intrínsecas de ese intercambio entre autoridades que actúan en diferentes esferas normativas que inevitablemente se superponen parcialmente.

En segundo lugar, el hecho de que la interpretación propuesta en esta investigación sea el producto de una deliberación marcada por la deferencia, implica que tanto las autoridades nacionales como los órganos del SIDH abandonan las viejas trincheras de la jerarquía, de la soberanía o de la mejor posición institucional para abrir paso a relaciones de interacción y coordinación mucho más complejas y constructivas. No solo hay reconocimiento mutuo, sino que existe contacto deliberativo, respetuoso y constructivo frente a un desacuerdo normativo.

En tercer lugar, la deliberación institucional rechaza la eficacia coercitiva exclusiva del SIDH y asume un concepto especial de implementación del derecho internacional de los derechos humanos. Bajo este parámetro, la implementación sugiere que las autoridades nacionales deben decidir los casos como si estos hubiesen sido resueltos por las autoridades del SIDH. Por el contrario, la eficacia coercitiva del SIDH apuesta por introducir dentro de la jurisdicción contenciosa del SIDH el mayor número de casos posible para que desde fuera ser corrija lo que se hace mal dentro de los Estados. La idea de implementación no contenciosa que aquí se defiende traslada la eficacia del SIDH a otros escenarios, como la función consultiva y la deliberación institucional; lo cual resulta más compatible con el principio de subsidiariedad material y genera mejores resultados para la protección efectiva de los derechos humanos.

En cuarto lugar, esta forma de resolver desacuerdos normativos complejos aumenta la legitimidad tanto de los órganos del SIDH como de las autoridades nacionales. Los primeros dejan de reclamar un espacio que las autoridades nacionales perciben como interferencia y pasan a formar parte de un trabajo colaborativo y coordinado para lograr la protección cooperativa de los derechos humanos. A su vez, los segundos entienden su rol dentro de un sistema internacionalizado y dentro de la aplicación de un derecho convencionalizado en el que la ley y la Constitución se leen de acuerdo con parámetros normativos internacionales.

En definitiva, hay mucho de valioso en resolver un desacuerdo normativo mediante la deliberación y la deferencia mutua, en comparación con la simple eficacia coercitiva de un texto normativo o de una autoridad que reclama mayor poder que otra. En el caso de la antinomia entre las funciones disciplinarias de la Procuraduría General de la Nación de Colombia y la actual comprensión del artículo 23.2 de la CADH fijada por la CIDH y la Corte IDH, se abre paso una interpretación de lege ferenda-como la que se ha sugerido- que avanzará en la mejor articulación de las autoridades nacionales e internacionales y de las normas nacionales con el derecho internacional de los derechos humanos. El objetivo último es siempre la mayor protección de todos los derechos humanos de quienes habitan los Estados que forman parte del Sistema Interamericano de Derechos Humanos.

\section{Bibliografía}

ACOSTA ALVARADO, Paola Andrea. "Los casos colombianos ante el sistema interamericano y el uso del margen de apreciación: ¿ausencia justificada?". En: ACOSTA ALVARADO, Paola Andrea; NUÑEZ POBLETE, Manuel. El margen de apreciación en el Sistema Interamericano de Derechos Humanos: Proyecciones Regionales y Nacionales. Universidad Nacional Autónoma de México, 2012.

Acosta-López, Juana Inés; LONDOÑO LÁZARO, María Carmelina. "El papel de la justicia nacional en la garantía del derecho a un recurso efectivo internacional". International Law. Revista Colombiana de Derecho Internacional, n. 16, 2010.

Arai-Takahashi, Yutaka. The margin of appreciation doctrine and the principle of proportionality in the jurisprudence of the ECHR. Intersentia, Antwerp, 2002. 
Besson, Samantha. "Subsidiarity in International Human Rights Law - What Is Subsidiary about Human Rights?”. The American Journal of Jurisprudence, v. 61, n. 1, p. 69-107, 2016.

Burgorgue-Larsen, Laurence; ÚBEDA DE TORRES, Amaya. The Inter-American Court of Human Rights. Case Law and Commentary. Oxford: Oxford University Press, 2011.

CAROZZA, Paolo. "Subsidiarity as a Structural Principle of International Human Rights Law". The American Journal of International Law, v. 97, n. 1, p. 38-79, 2003.

CIDH. Informe 92/09. Caso 12.668. Fondo, Leopoldo López Mendoza, Venezuela, 8 de agosto de 2009.

CIDH. Informe de Fondo No. 130/17. Caso 13.044. Gustavo Francisco Petro Urrego. 25 de octubre de 2017.

CIDH. Resolución 5 de 2014, Medida Cautelar No. 374-13. 18 de marzo de 2014.

CONSEJO DE ESTADO. Sala Plena de lo Contencioso Administrativo. Auto del 13 de febrero de 2018. Radicado No. 11001032500020140036000. Magistrado Ponente: César Palomino Cortés.

Consejo de Estado. Sala Plena de lo Contencioso Administrativo. Sentencia del 15 de noviembre de 2017. Radicado No. 11001032500020140036000 . Magistrado Ponente: César Palomino Cortés.

CONSEJO SUPERIOR DE LA JUDICATURA. Sala Jurisdiccional Disciplinaria, Sentencia del 6 de marzo de 2014, Radicado No. 11001110200020130812001, Salvamento de Voto del Magistrado Néstor Osuna Patiño.

CONTRERAS, Pablo. "Control de convencionalidad, deferencia internacional y discreción nacional en la jurisprudencia de la Corte Interamericana de Derechos Humanos". Revista Ius et Praxis, v. 20, n. 2, p. $242-$ 243, 2014.

CORTE CONSTITUCIONAL DE COLOMBIA. Sentencia C-028 de 2006.

CORTE CONSTITUCIONAL DE COLOMBIA. Sentencia C-1076 de 2002.

CORTE CONSTITUCIONAL DE COLOMBIA. Sentencia C-124 de 2003.

CORTE CONSTITUCIONAL DE COLOMBIA. Sentencia C-181 de 2002.

CORTE CONSTITUCIONAL DE COLOMBIA. Sentencia C-948 de 2002.

CORTE CONSTITUCIONAL DE COLOMBIA. Sentencia SU-712 de 2013.

CORTE CONSTITUCIONAL DE COLOMBIA. Sentencia T-514 de 2016.

CORTE IDH. Caso Artavia Murillo y otros ("Fecundación in vitro") Vs. Costa Rica. Excepciones Preliminares, Fondo, Reparaciones y Costas. Sentencia de 28 noviembre de 2012. Serie C No. 257.

CORTE IDH. Caso Brewer Carías Vs. Venezuela. Excepciones Preliminares. Sentencia de 26 de mayo de 2014. Serie C No. 278.

CORTE IDH. Caso Cantoral Benavides Vs. Perú. Excepciones Preliminares. Sentencia de 3 de septiembre de 1998. Serie C No. 40.

CORTE IDH. Caso de la "Masacre de Mapiripán" Vs. Colombia. Sentencia de 15 de septiembre de 2005. Serie C No. 134.

CORTE IDH. Caso Duque Vs. Colombia. Excepciones Preliminares, Fondo, Reparaciones y Costas. Sentencia de 26 de febrero de 2016. Serie C No. 310.

CORTE IDH. Caso González. Medina y familiares Vs. República Dominicana. Excepciones Preliminares, Fondo, Reparaciones y Costas. Sentencia de 27 de febrero de 2012. Serie C No. 240. 
CORTE IDH. Caso Herrera Ulloa Vs. Costa Rica. Excepciones Preliminares, Fondo, Reparaciones y Costas. Sentencia de 2 de julio de 2004. Serie C No. 107.

CORTE IDH. Caso López. Mendoza Vs. Venezuela. Fondo Reparaciones y Costas. Sentencia de 1 de septiembre de 2011 Serie C No. 233.

CORTE IDH. Caso Nogueira de Carvalho y otro Vs. Brasil. Excepciones Preliminares y Fondo. Sentencia de 28 de noviembre de 2006. Serie C No. 161.

CORTE IDH. Caso Rodríguez. Veray otros (Desaparecidos del Palacio de Justicia) Vs. Colombia. Excepciones Preliminares, Fondo, Reparaciones y Costas. Sentencia de 14 de noviembre de 2014. Serie C No. 287.

CORTE IDH. Caso Valle Jaramillo y otros Vs. Colombia. Fondo, Reparaciones y Costas. Sentencia de 27 de noviembre de 2008. Serie C No. 192.

CORTE IDH. Excepciones al agotamiento de los recursos internos (Arts. 46.1, 46.2. a y 46.2.b, Convención Americana sobre Derechos Humanos). Opinión Consultiva OC-11/90 de 10 de agosto de 1990. Serie A No. 11.

CORTE SUPREMA DE JUSTICIA DE LA NACIÓN ARGENTINA. Sentencia de 14 de febrero de 2017. CSJ368/1998(34-M)/CS1. Ministerio de Relaciones Exteriores y Cultos/informe sentencia dictada en el caso "Fontevecchia y D’Amico vs. Argentina" por la Corte Interamericana de Derechos Humanos.

DUHAIME, Bernard. "Subsidiarity in the Americas. What room is there for deference in the Inter-American System?”. En: GRUSZCZYNSKI, Lukasz; WERNER, Wouter. Deference in International Courts and Tribunals. Oxford: Oxford University Press, 2014. p. 291-292.

FOLLESDAL, Andreas. "Exporting the margin of appreciation: Lessons for the Inter-American Court of Human Rights”. International Journal of Constitutional Law, v. 15, n. 2, p. 359-371, 2017.

GARCÍA ROCA, Javier. El margen de apreciación nacional en la interpretación del Convenio Europeo de Derechos Humanos: soberanía e integración. Thomson Reuters-Civitas, España, 2010.

GREER, Steven. "The margin of appreciation: interpretation and discretion under the European Convention of Human Rights”. Human Rights Files, n 17, Consejo de Europa, Estrasburgo, 2010.

GRUSZCZYNSKI, Lukasz y Werner, Wouter. Deference in International Courts and Tribunals. Oxford University Press, Oxford, 2014.

HENAO, Juan Carlos. "Las formas de reparación en la responsabilidad del Estado: hacia su unificación sustancial en todas las acciones contra el Estado". Revista de Derecho Privado, n. 28, p. 277-366, 2015.

KLETZEL, Gabriela et al. "Democracia y subsidiariedad". En: BARRETO MAIA, Camila et al. Desafios del Sistema Interamericano de Derechos Humanos. Nuevos tiempos, viejos retos. Bogotá: DeJusticia, 2015. p. 191-228.

LEONHARDSEN, Erlend. "Treaty Change, Arbitral Practice and the Search for a Balance: Standards of Review and the Margin of Appreciation in International Investment Law”. En: GRUSZCZYNSKI, Lukasz; WERNER, Wouter. Deference in International Courts and Tribunals. Oxford: Oxford University Press, 2014. p. 135-151.

MOWBRAY, Alastair. "Subsidiarity and the European Convention on Human Rights". Human Rights Law Review, v. 15, n. 2, p. 313-341, 2015.

NEUMAN, Gerald. "Subsidiarity". En: SHELTON, Dinah (Ed.). The Oxford Handbook of International Human Rights Law. Oxford: Oxford University Press, 2013.

PASQUALUCCI, Jo M. The Practice and Procedure of the Inter-American Court of Human Rights. Cambridge: Cambridge University Press, 2013.

RAGNI, Chiara. "Standard of Review and the Margin of Appreciation before the International Court of 
Justice". En: GRUSZCZYNSKI, Lukasz; WERNER, Wouter. Deference in International Courts and Tribunals. Oxford: Oxford University Press, 2014. p. 319-336.

ROA ROA, Jorge Ernesto. "Las antinomias entre las Constituciones y la Convención Americana sobre Derechos Humanos: el gran dilema del juez constitucional y convencional interamericano". En: SAIZ ARNAIZ, Alejandro. (Coord.); SOLANES, Joan; ROA, Jorge (Ed.). Diálogos judiciales en el Sistema Interamericano de Derechos Humanos. Valencia: Tirant lo Blanch, 2017. p. 139-148.

SAGÜÉS, Néstor Pedro. La Constitución bajo tensión. México: Instituto de Estudios Constitucionales del Estado de Querétaro, 2016.

SAUL, Matthew. "The European Court of Human Rights' Margin of Appreciation and the Processes of National Parliaments". Human Rights Law Review, v. 15, n. 4, 2015.

SPANO, Robert. "Universality or Diversity of Human Rights? Strasbourg in the Age of Subsidiarity". Human Rights Law Review, v. 14, n. 3, p. 500.

TEDH. Asunto Handyside v. Reino Unido, n 5493/72, sentencia del 7 diciembre de 1976.

TEDH. Asunto Vuckković y otros v. Serbia, no 17153/11, sentencia de 25 de marzo de 2014.

TOJO, Liliana; ELIZALDE, Pilar. "Competencia de la Comisión Interamericana de Derechos Humanos". En: STEINER, Christian; URIBE, Patricia. (Ed.). Convención Americana sobre Derechos Humanos. Comentario. Bogotá: Temis-Konrad Adenauer Stiftung, 2014.

TORRES PÉREZ, Aida. "La independencia de la Corte Interamericana de Derechos Humanos desde una perspectiva institucional”. En: IGLESIAS VILA, Marisa et al. Derechos Humanos: posibilidades teóricas y desafíos prácticos. Buenos Aires: Libraria, 2014. p. 66-88.

TRIBUNAL ADMINISTRATIVO DE CUNDINAMARCA. Sección Segunda, Subsección A, Sentencia de 13 de enero de 2014, Proceso A.T. No. 2013-07052-00, Magistrado Ponente: José María Armenta Fuentes.

TRIBUNAL CONTENCIOSO ADMINISTRATIVO DE LA GUAJIRA. Sentencia de 5 de junio de 2018. Radicado No. 44-001-23-40-000-2018-00062-00. Magistrada Ponente: Carmen Dalis Argote Solano.

UPRIMNY, Rodrigo; GUZMÁN, Diana. "En búsqueda de un concepto transformador y participativo para las reparaciones en contextos transicionales". Revista Colombiana de Derecho Internacional, n. 17, p. 231-286, 2010.

YOUROW, Howard Charles. The margin of appreciation doctrine in the dynamics of European Human Rights jurisprudence. The Hague: Kluwer Law International, 1996. 
Para publicar na revista Brasileira de Políticas Públicas, acesse o endereço eletrônico www.rbpp.uniceub.br

Observe as normas de publicação, para facilitar e agilizar o trabalho de edição. 